\title{
REHABILITACIÓN Y REUTILIZACIÓN DEL PATRIMONIO URBANO. LOS CENTROS HISTÓRICOS DE NUEVAS CAPITALES POLÍTICAS ESPAÑOLAS PATRIMONIO DE LA HUMANIDAD
}

\author{
Ana Eulalia Aparicio Guerrero* \\ Óscar Serrano Gil** \\ Universidad de Castilla-La Mancha
}

Daniel León Irujo***

Consorcio Ciudad de Cuenca

\section{RESUMEN}

La constitución del Estado de las Autonomías y la necesidad de instalar gran parte de los órganos de gobierno en las capitales regionales; las oportunidades de funciones como la sociocultural, la universitaria y la turística; y las innovaciones en el terreno de la gestión; han propiciado el diseño y puesta en práctica de distintas políticas urbanas orientadas a revitalizar los cascos históricos y promocionar el desarrollo del turismo cultural, iniciándose así una lenta recuperación y una puesta en valor de su patrimonio, políticas que han sido avaladas por la UNESCO con el reconocimiento de los centros históricos de varias ciudades como Patrimonio de la Humanidad. Es el caso, entre otras, de Santiago de Compostela y Toledo. Aun aceptando que todavía falta mucho por hacer, la situación de sus cascos históricos es mucho más favorable que la existente a comienzos de los ochenta.

Palabras clave: centros históricos; revitalización; funciones culturales; turísticas; administrativas y universitarias.

Fecha de recepción: 6 de marzo de 2018.

Fecha de aceptación: 30 de octubre de 2018.

* Departamento de Geografía y Ordenación del Territorio. Universidad de Castilla-La Mancha. Avda. Los Alfares, 44.16071 CUENCA (España).E-mail: Ana.Aparicio@uclm.es

** Departamento de Geografía y Ordenación del Territorio. Universidad de Castilla-La Mancha. Camino Pozuelo s/n. 16071 CUENCA (España).E-mail: Oscar.Serrano@uclm.es

**** Consorcio Ciudad de Cuenca Colón, 6, $3^{\mathrm{a}}$ planta. 16002 CUENCA (España). E-mail: gerencia@consorciodecuenca.es 


\title{
Rehabilitation and reuse of the urban heritage. \\ The Historical Centers of new Spanish political capitals declared as World Heritage
}

\begin{abstract}
The constitution of the State of the Autonomies and the need to set up a large part of the governing bodies in the regional capitals, the opportunities of managing the socio-cultural, university and tourist functions, among others, and innovations in the field of management have encouraged the design and implementation of different urban policies aimed at revitalizing the historical centers and promoting the development of cultural tourism, thus initiating a slow recovery and a value enhancement of their heritage. These policies have been endorsed by UNESCO with the recognition of the historical centers of several cities as World Heritage. This is the case of Santiago de Compostela and Toledo. Even accepting that there is still much to be done, the situation of their historical centers is noticeably more favorable than that existing at the beginning of the 1980's.
\end{abstract}

Keywords: historical centers; revitalization; cultural; tourist; administrative and university functions.

\section{INTRODUCCIÓN. EL SISTEMA AUTONÓMICO, LAS NUEVAS CAPITALI- DADES Y LOS CENTROS HISTÓRICOS}

La nueva configuración político-administrativa del Estado, con la creación del sistema autonómico español en 1977, ha supuesto que las nuevas capitales regionales aumenten su capacidad para captar recursos y promocionarse. En las comunidades multiprovinciales las capitales se han resituado en el sistema urbano regional, aun siendo ciudades de menor población y actividad que otras de su entorno, produciéndose la concentración de competencias en la capital.

La problemática de los centros históricos de estas ciudades suele presentar bastantes elementos comunes: deterioro de la edificación, precarias condiciones de habitabilidad, pérdida de vitalidad funcional, vaciamiento demográfico, envejecimiento, infrautilización residencial, dificultades de movilidad y de aparcamiento, y precario nivel de equipamientos y servicios, entre otros. Sin embargo, la existencia de problemáticas comunes no implica que se deban generalizar los modelos de intervención, pues existe una gran diversidad de situaciones. Para diseñar y gestionar las políticas de protección y recuperación urbana, es necesario tener muy presente la singularidad de cada centro histórico y su dinámica interna. Según Troitiño (2003) existen, al menos, cuatro tipos de situaciones: centros históricos que han dejado de ser el centro económico pero conservan la centralidad simbólica y cultural; centros donde lo histórico y lo funcional permiten conservar una cierta centralidad; centros históricos cuya identidad urbana se ha perdido o difuminado en estructuras urbanas transformadas o degradadas; y centros históricos que siguen siendo el centro de la ciudad actual. Estos últimos son los casos de Toledo y Santiago de Compostela, núcleos en los que se va a centrar nuestro estudio como ejemplos de nuevas capitalidades políticas. 
En este artículo presentaremos las experiencias de renovación urbana y revitalización llevadas a cabo en las capitales de dos regiones, la gallega y la castellano-manchega, y más en concreto en los centros históricos de estas dos ciudades Patrimonio de la Humanidad, mediante la exposición de algunas de las intervenciones realizadas en los últimos treinta y cinco años dirigidas a la implantación de nuevos usos y servicios en bienes patrimoniales históricos infrautilizados o en desuso.

En la primera parte del estudio incidiremos en las medidas legales de protección del Patrimonio Histórico a escala nacional y regional, para pasar posteriormente a analizar el planeamiento urbanístico a escala general y especial en dos estudios de caso a escala macro, el Centro Histórico de Santiago de Compostela y el Centro Histórico de Toledo; a exponer las políticas urbanas diseñadas a escala regional con el fin de revitalizar estos espacios; y a analizar los instrumentos de gestión encargados de coordinar a los distintos niveles de la administración. Finalmente nos centraremos en una selección de estudios de caso a escala micro asociados a usos administrativos, socioculturales, turísticos, educativos y residenciales; y terminaremos con las conclusiones finales de la investigación.

Las políticas de rehabilitación se centran en la conservación de una zona no solo por sus valores intrínsecos, sino también por sus potencialidades de desarrollo económico en el marco de un programa de recuperación integral de las dimensiones social y funcional. La política de rehabilitación, además de estar vinculada a la protección del patrimonio histórico artístico, está ligada al desarrollo, puesto que el patrimonio histórico constituye un activo económico (Aparicio, 2004), y la economía de muchas de estas ciudades está cada vez más estrechamente ligada al turismo. Las ciudades históricas se han convertido en centros receptores de turismo nacional y extranjero, atraído por la historia, por el patrimonio arquitectónico y urbanístico, por la cultura y también por el medio ambiente urbano singular, siendo uno de los más importantes focos de atracción turística de nuestro tiempo.

En el caso de la capital gallega, al formar parte del corredor litoral atlántico y tener una buena relación con la Galicia interior en cuanto a comunicaciones y servicios, la sitúa en una posición equilibradora y articuladora del sistema urbano gallego, reforzada por sus funciones simbólicas y representativas como capital de Galicia y ciudad Patrimonio de la Humanidad, presentándose actualmente como un centro regional especializado, con fuerte presencia del terciario público (Estévez, 2001), y con un espacio turístico reducido que utiliza fundamentalmente el patrimonio concentrado en su centro histórico (Santos, 2006). El Centro Histórico de Santiago de Compostela mantuvo una notable vitalidad hasta los años 80. La ciudad presentaba unas funciones regionales muy definidas y especializadas: la religiosa desde el siglo XII, la universitaria desde el siglo XVI, la sanitaria desde el siglo XIX, además ser el centro de transportes y de comercio de una extensa zona rural (Precedo, 1998). A pesar de ello, ocupaba el quinto lugar en la jerarquía de centralidad terciaria del sistema de ciudades de Galicia. A partir de entonces, surgieron ciertos síntomas de crisis residencial, demográfica, funcional y material: viviendas vacías o con necesidades de alguna actuación de rehabilitación, población envejecida, problemas de tráfico y congestión y espacios marginales y socialmente degradados ${ }^{1}$. Después de su

1 Protección y rehabilitación de la ciudad histórica e integración con su entorno natural (Santiago de Compostela, España) 26-06-2002. Disponible en http://habitat.aq.upm.es/bpes/onu02/bp205.html 
designación como capital autonómica se sitúa en el segundo puesto (Precedo y Villarino, 1995), siendo actualmente la ciudad con mayor proyección internacional desde el punto de vista del turismo cultural, gracias a las estrategias de marketing puestas en marcha en torno al Camino de Santiago.

En el caso de Toledo, su primacía en la red urbana castellano-manchega, junto con Albacete, hizo de la primera la capital regional, erigiéndose rápidamente en un sólido centro administrativo y político de la comunidad autónoma (Panadero y Pillet, 1999). Su ubicación como continuación del corredor industrial al suroeste de Madrid y sus recursos culturales fueron claves en la decisión final. Factores como el aumento del precio de la vivienda en Madrid y la mejora de las comunicaciones con el Tren de Alta Velocidad han provocado un aumento de la población de algo más de un $20 \%$ en la última década. No obstante, los servicios se dirigen cada vez más al visitante y no al residente, y los apartamentos turísticos está expulsando a la población a los barrios periféricos.

\section{MEDIDAS LEGALES DE PROTECCIÓN DEL PATRIMONIO HISTÓRICO}

La vigente Ley 16/1985, de 25 de junio, del Patrimonio Histórico Español, surgió de la necesidad de paliar la dispersión normativa ocasionada por la multitud de fórmulas legales con las que, a lo largo de medio siglo, se quisieron afrontar situaciones no previstas o inexistentes en el momento de la promulgación de la anterior Ley de 1933. El objetivo de la Ley es la protección y acrecentamiento del patrimonio así como su transmisión a las generaciones futuras, y para ello establece que los bienes más relevantes del Patrimonio Histórico deben ser inventariados o declarados de interés cultural -Bien de Interés Cultural (BIC) - distinguiendo cinco categorías: Monumentos del Patrimonio Histórico de España, Jardín Histórico, Conjunto Histórico, Sitio Histórico y Zona Arqueológica. Además, la Ley de Suelo aprobada mediante el Real Decreto Legislativo 2/2008, de 20 de junio conecta con los objetivos del Programa de Buenas Prácticas y Liderazgo Local promovido por Naciones Unidas, cuando plantea la necesidad de recuperar la ciudad como creación cultural colectiva y favorecer su rehabilitación y el fomento de su uso (Corredor, 2009).

En Galicia, la Ley 8/1995, de 30 de octubre del Patrimonio Cultural respondió a la especificidad que como nacionalidad histórica posee la región en materia cultural y establecía que los inmuebles, especialmente los monumentos, al estar integrados en un territorio, no constituyen elementos aislados, y por consiguiente los proyectos de intervención deberían ser diseñados por equipos pluridisciplinares. También reconocía el importante papel de las corporaciones locales y de la iglesia católica en materia de patrimonio cultu$\mathrm{ral}^{2}$. La Ley 5/2016, de 4 de mayo del Patrimonio Cultural de Galicia, actualmente vigente, parte igualmente de la consideración de que los bienes inmuebles están integrados en un contexto y por consiguiente aconseja que se actúe desde un punto de vista multidisciplinar. Novedades de la ley en vigor son: el establecimiento de la zona de amortiguamiento o entorno de protección, la creación del Centro de Patrimonio Cultural y la Red y el Sistema de Museos de Galicia.

2 Ley 8/1995, de 30 de octubre, del Patrimonio Cultural de Galicia. Noticias jurídicas. Base de datos de legislación. Disponible en http://noticias.juridicas.com/base_datos/CCAA/ga-18-1995.html 
En Castilla-La Mancha, la Ley 4/1990 de 30 de mayo de Patrimonio Histórico de Castilla-La Mancha tiene como objetivo la protección, acrecentamiento y transmisión a las generaciones futuras del Patrimonio Histórico, aunque la Junta colabora con la administración del Estado, las corporaciones locales y con instituciones públicas o privadas, con el fin de garantizar la conservación del Patrimonio Histórico como parte integrante del Patrimonio Histórico Español. Esta Ley representa un avance en la relación entre protección del patrimonio histórico y planeamiento urbanístico, ya que obligaba a que en toda revisión del planeamiento urbanístico se incluyeran catálogos de edificios monumentales y se definieran las zonas consideradas como entornos monumentales y sus condiciones urbanísticas. En la tramitación del expediente de declaración como BIC de un conjunto histórico deben considerarse sus relaciones con el área territorial a la que pertenece, la protección de los accidentes geográficos y parajes naturales de su entorno, el mantenimiento de la estructura urbana y arquitectónica, las características generales de su ambiente, y las necesarias adecuaciones edificatorias a los nuevos usos. La Ley 4/2013, de 16 de mayo de Patrimonio Cultural de Castilla-La Mancha ${ }^{3}$, actualmente vigente, amplia lo recogido en la Ley 4/1990 en aspectos como la definición del entorno de protección de un bien, la descripción del contenido de un Plan Especial y la regulación del Inventario de los Bienes del Patrimonio Cultural.

\section{EL PLANEAMIENTO URBANÍSTICO. EL IMPULSO DE LA PROTECCIÓN.}

El planeamiento urbanístico existente en España a mediados de la década de los setenta carecía de preocupación por la dimensión histórica de la ciudad estando al servicio de la destrucción o de la transformación radical de los centros históricos. Los ayuntamientos democráticos, constituidos en 1979, impulsarán la protección en el planeamiento general y la puesta en marcha de las primeras iniciativas de planeamiento especial (Pol, 1998; Troitiño, 2003).

\subsection{Santiago de Compostela. Plan Especial de Protección y Rehabilitación de la Ciudad Histórica}

El Centro Histórico de Santiago de Compostela se declara Conjunto Histórico-Artístico en 1944, y en 1966 se aprueba un Plan General en el que se establecen unas zonas de protección en el perímetro del mismo. Este plan se revisará en 1974 con criterios desarrollistas. El Plan General de Ordenación Urbana (PGOU) de 1989 plantea la ordenación del territorio preservando las zonas montañosas y de cultivo, los cauces, el entorno monumental y los más de 100 pequeños núcleos de población comprendidos en el término municipal, y amplía la delimitación de la ciudad histórica a 170 has. En la ciudad se distingue la fachada de poniente que se corresponde con el río, el monte y el núcleo histórico desarrollado en torno a la catedral, y la fachada de levante que se corresponde con la zona nueva. En la primera, y según lo establecido en el Plan General "se ha de actuar ordenando, conservando, rehabilitando, construyendo, peatonalizando, cuidando

3 Disponible en https://www.boe.es/buscar/pdf/2013/BOE-A-2013-10415-consolidado.pdf 
lo grande y lo pequeño". Se protege física y ambientalmente; aquí se emplazan los dos campus universitarios exteriores al casco urbano. En la segunda se abordará el crecimiento de la ciudad mediante la implantación de las infraestructuras y equipamientos adecuados a los nuevos roles de la ciudad, evitando la excesiva presión inmobiliaria sobre la ciudad histórica (Estévez, 2001).

El 30 de octubre de 2008 se aprueba el Texto Refundido Final del Plan General de Ordenación Municipal (PGOM). Santiago se proyecta hacia el futuro aprovechando las nuevas oportunidades que le otorga una administración local renovada y el impulso de políticas para atraer avanzadas infraestructuras y equipamientos. El Plan General contempló la existencia de museos, centros culturales, aparcamientos y polideportivos, ordenó el tráfico que asfixiaba su trama medieval y formuló los objetivos de la política urbana. Por primera vez el conjunto histórico y su recuperación son objeto de la reflexión urbanística y el objetivo de la propuesta de ordenación de la ciudad. El sistema general de comunicaciones, la localización de los grandes usos y la previsión de las áreas de crecimiento obedecen al criterio de propiciar una estructura urbana compacta en relación a la ciudad histórica en una escala todavía peatonal, de modo que permita a esta parte de la ciudad mantener y reforzar las funciones urbanas que la mantienen viva.

El desarrollo simultáneo de los trabajos del Plan General Municipal con las fases iniciales del Plan Especial de Protección y Rehabilitación de la Ciudad Histórica permitió concebir como un todo la ordenación de la ciudad y establecer como su objetivo central la recuperación de la ciudad histórica. Las prioridades fueron establecidas en su PGOM y desarrolladas en su Plan Especial. Ambos iniciaron su formulación simultáneamente (1988) a cargo del mismo equipo de urbanistas, de tal forma que no se produjeron esperas hasta la tramitación del Plan Especial. Varios proyectos relevantes fueron ejecutados entre 1990 y 1994, años antes de aprobarse definitivamente el Plan Especial en 1997: el Centro Gallego de Arte Contemporáneo y el Parque de Santo Domingo de Bonaval; la ampliación y reforma del estacionamiento y de la avenida de Juan XXIII; y el nuevo aparcamiento de San Clemente, actuaciones estas dos últimas que permitieron abordar también la peatonalización de la ciudad histórica. El ámbito de la Ciudad Histórica de Santiago fue delimitado por el Plan General Municipal, siendo reajustado por el Plan Especial de Protección y Rehabilitación (1997). Tiene una superficie de 169,9 hectáreas y comprende el antiguo

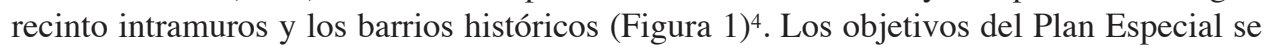
centraron en la recuperación urbana, con la conservación y restauración de la totalidad de edificios y estructuras urbanas; la recuperación funcional, con la potenciación de su función central y su vocación institucional y económica; la transformación urbanística de las áreas de contacto con la ciudad contemporánea; y la compatibilización de la rehabilitación de arquitecturas heredadas con la presencia de la arquitectura contemporánea (Dalda, 2007; Estévez, 2001).

El Plan Especial ha merecido el Premio Europeo de Urbanismo 1997-98 de la Comisión Europea y el Consejo Europeo de Urbanistas, junto con otros reconocimientos

4 INSTITUTO GALEGO DA VIVIENDA E SOLO. "Casco Histórico de Santiago de Compostela. Área de rehabilitación de Centro Histórico", disponible en https://ari-igvs.xunta.gal/es/node/52. 
nacionales e internacionales ${ }^{5}$. Además, la planificación urbanística de la ciudad y su integración ambiental han sido distinguidas como Buenas Prácticas en el Concurso de Buenas Prácticas de Hábitat 2002 patrocinado por la Municipalidad de Dubai (Dalda, 2007) y catalogadas como AWARD.

El PGOM aprobado inicialmente en 2018 recoge entre otras actuaciones, la integración de las grandes infraestructuras -aeropuerto, Tren de Alta Velocidad, autopista de Ourense, Transcantábrica, y otras-; la planificación del área urbana con la conservación del centro histórico; la descentralización de servicios y el respeto al medioambiente; y un convenio urbanístico firmado con la Universidad de Santiago de Compostela ${ }^{6}$.

\subsection{Toledo. Plan Especial del Casco Histórico}

En el caso de Toledo, la declaración de la ciudad como Monumento Nacional mediante Decreto de 9 de marzo de 1940 provoca la redacción del Plan General de 1943, que incluye unas normas que regulaban alturas, volúmenes, materiales y colores, pero eludían aspectos socioeconómicos, potenciando la ciudad monumental y representativa, aunque no tuviera vida ni actividad (Busquets, 2000). No obstante, es el único documento de planeamiento que ha formulado propuestas concretas para el casco histórico. Tanto el Plan General de 1964 como el de 1986 eluden el problema, siendo este último el que remite a la redacción del Plan Especial, recomendando no efectuar derribos salvo ruinas inminentes hasta no tener un Plan Especial.

Durante muchos años, las actuaciones en el casco histórico de Toledo se rigen por los criterios establecidos por las diferentes Comisiones de Patrimonio. La situación de ambigüedad urbanística se vio paliada con las Instrucciones de Bellas Artes de 1968 que intentan clarificar los criterios de actuación en el conjunto histórico con prescripciones más claras de carácter volumétrico y estético, y que se convertirían de hecho en las Ordenanzas del Casco Histórico. Se trata de directrices generales de aspecto exterior más que propiamente urbanísticas, que afectan a la zona definida como histórico-artística (recinto amurallado, puertas y puentes del Tajo, Circo Romano y castillo San Servando), definiendo el entorno (zona de respeto y protección del paisaje y silueta urbana), así como zonas especiales (cigarrales y acceso a Toledo desde Madrid) (Busquet, 2000) (Figura 2).

La modificación puntual número 29 realizada este mismo año tiene por objeto la redacción de un documento Refundido de Plan General Municipal de Ordenación Urbana de Toledo de 1986 en el que se incluyan todas las modificaciones puntuales del Plan General desde su entrada en vigor, de manera que constituya un único documento que recoja toda la normativa vigente en la ciudad. Las actuaciones relativas al casco histórico se centran en la modificación del catálogo de diversos inmuebles ubicados en este espacio ${ }^{7}$.

5 Protección y rehabilitación de la ciudad histórica e integración con su entorno natural (Santiago de Compostela, España) 26-06-2002. Disponible en http://habitat.aq.upm.es/bpes/onu02/bp205.html

6 Plan General de Ordenación Municipal 2018. Plataforma GaliciaDigital. El portal de Galicia para el Mundo. Viernes, 12 de octubre de 2018. Disponible en https//www.galiciadigital.com

7 Ayuntamiento de Toledo (2018): Modificación puntual número 29 del Plan General Municipal de Ordenación Urbana de Toledo de 1986. Sede electrónica, www.toledo.es 
Figura 1

CENTRO HISTÓRICO DE SANTIAGO DE COMPOSTELA

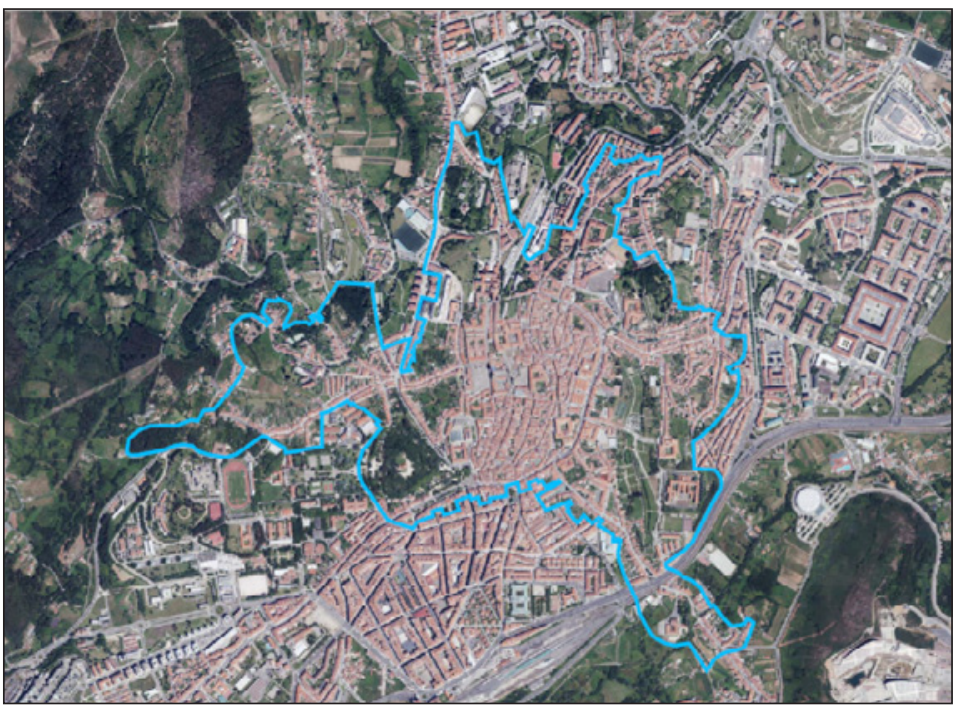

Fuente: Instituto Galego da Vivienda e Solo. Disponible en: https://ari-igvs.xunta.gal/ es/node/52.

Figura 2

CENTRO HISTÓRICO DE TOLEDO

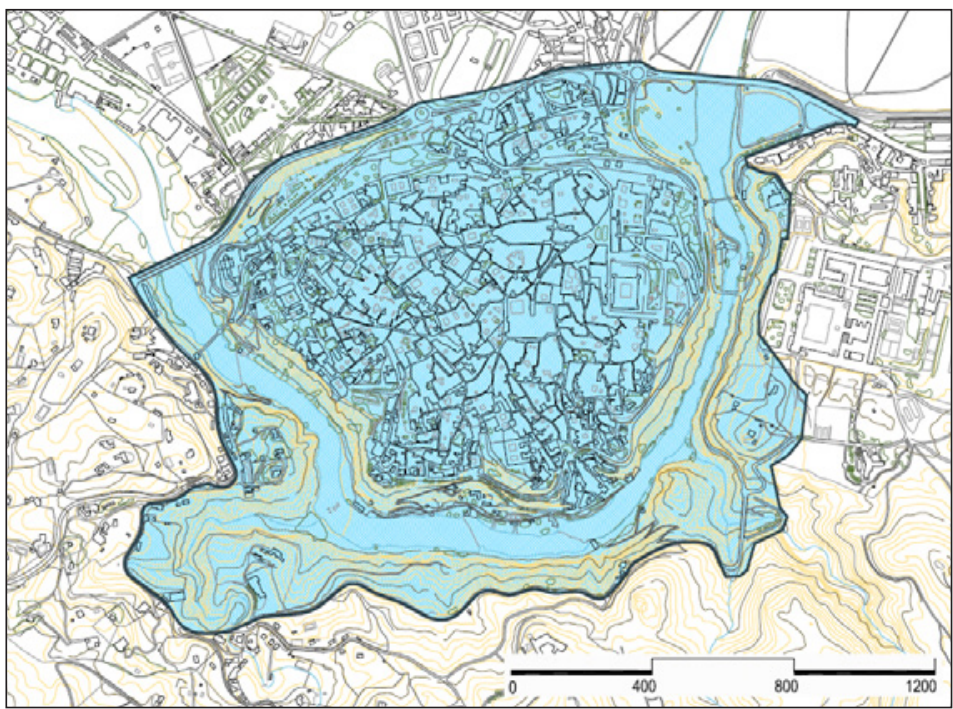

Fuente: Ayuntamiento de Toledo. Disponible en: https://www.toledo.es/serviciosmunicipales/urbanismo 
En 1997, doce años después de ser calificada por la UNESCO Patrimonio de la Humanidad entra en vigor el Plan Especial del Casco Histórico, resultado de una amplia colaboración institucional (Ayuntamiento, Consejería de Cultura, Ministerio de Cultura y otras instituciones privadas). El ámbito de la declaración incluye al conjunto del Casco Histórico en su zona intramuros (Figura 2). En él se realiza una valoración del paisaje urbano, remitiendo en el caso de los acabados de fachadas, materiales y colores a un estudio posterior que se concretó en el Plan de Color del Casco Histórico (Almarcha et al., 2011); se fija una serie de categorías de intervención que van desde el mantenimiento ordinario, el mantenimiento extraordinario (rehabilitación), la reestructuración edificatoria y la reestructuración urbanística; se plantean actuaciones que favorecen la accesibilidad (ensanchamientos viarios, aparcamientos y remontes peatonales); y se propicia el aumento de espacios libres (plazas y jardines, espacios libres no edificables y miradores). Algunas actuaciones ya abordadas, según los autores del libro Paisajes de los Conjuntos Históricos de Castilla-La Mancha (2011), tienen una incidencia muy importante en el paisaje urbano como ocurre con los dos remontes mecánicos: el de la fachada norte y el relacionado con el Palacio de Congresos de la cara oeste. El Avance del plan se centra en acciones de proyección de Toledo como capital monumental con funciones culturales, turísticas, administrativas, representativas, residenciales, y acciones de puesta en valor del patrimonio existente como elementos activos de la ciudad y el fortalecimiento de la residencia como actividad básica del Casco (Almarcha et al., 2011). Además, en él se superan las nociones de 'centro histórico' o de 'conjunto histórico' al tener en cuenta el contexto urbano más amplio y su medio geográfico (UNESCO, 2010, art. 9), es decir, la topografía, la geomorfología y las características naturales, su entorno edificado, sus infraestructuras de superficie y subterráneas, sus espacios verdes y jardines, sus planos de ocupación de suelos, su organización del espacio, y todos los demás elementos constitutivos de la estructura urbana, además de los valores sociales y culturales y los procesos económicos (Lalana, 2011).

\section{INSTRUMENTOS DE GESTIÓN PARA LA REVITALIZACIÓN DE LOS CEN- TROS HISTÓRICOS}

Para garantizar la operatividad del planeamiento son necesarios importantes niveles de inversión y un liderazgo institucional de las administraciones públicas, y muy especialmente de la municipal. En la gestión del planeamiento especial se ha optado en las dos ciudades analizadas por consorcios.

\subsection{Santiago de Compostela. Ciudad pionera en la gestión del Plan Especial a través de un Consorcio}

Santiago de Compostela fue la primera en constituir un Real Patronato en 1991. Después, y a imitación del de Santiago de Compostela, se han creado otros dos reales patronatos en España, los de Toledo y Cuenca. Un año más tarde, en 1992, el Real Patronato de Santiago se dota de un instrumento operativo, el Consorcio Ciudad de Santiago, de titularidad municipal, personalidad jurídica y patrimonio propios. Administración pública 
participada por el Gobierno de España (60\%), el Gobierno regional de Galicia (35\%) y el Gobierno municipal de Santiago de Compostela (5\%), sus ámbitos de actuación se centran en tres áreas: recuperación urbana -viviendas, locales comerciales y monumentos-; estudio e información de la ciudad histórica; y dinamización cultural, mediante la potenciación de las actividades turísticas y culturales vinculadas al itinerario jacobeo. El Consorcio propone, promueve y tutela, financiera y técnicamente hasta su materialización, iniciativas y proyectos, fomentando la coordinación y cooperación entre las diversas administraciones y agentes ${ }^{8}$, y aprobando todas las decisiones por unanimidad (Troitiño, 2003). Para mejorar la gestión se crea en 1994 la Oficina de Conservación y Rehabilitación de la Ciudad Histórica (OCiHR) que pondrá en marcha la recuperación urbana diseñada en el Plan Especial, con dos estrategias claras: la atención directa, personal y cualificada a los usuarios, y la formación de los agentes implicados (técnicos y empresas) que garanticen en el futuro la conservación de la ciudad histórica.

La política cultural del Consorcio de Santiago está íntimamente ligada a las políticas públicas de rehabilitación y conservación del patrimonio de la ciudad histórica, tanto en el campo de la música (mediante la financiación de la Real Filarmonía de Galicia, la organización del Festival de Músicas Contemplativas, y el Compostela Organum Festival, entre otros), de la ciencia (programa Conciencia y Premio Fonseca de divulgación científica), como en el de la investigación y editorial, con la publicación de cerca de un centenar de títulos desde 1993. La recuperación urbana de la ciudad histórica ha alcanzado una importante difusión nacional e internacional. Además de la presencia de la ciudad en múltiples foros, la experiencia compostelana ha sido transmitida a través de la Asamblea de Ciudades Patrimonio Mundial a distintas ciudades de los cinco continentes, manteniendo relaciones de cooperación internacional con varias ciudades latinoamericanas. La pequeña dimensión de la ciudad, 120.000 habitantes, el carácter integral de las actuaciones, su directa relación con los problemas más concretos de los ciudadanos, y el protagonismo directo de una Administración local con recursos técnicos y financieros limitados, hace especialmente transmisible esta experiencia: un proyecto de base local que, identificando las oportunidades de sus recursos -culturales y ambientales- consiguió llamar la atención de las autoridades hasta convertirse en un proyecto de interés estatal que ha servido para proyectar internacionalmente a la ciudad, a su patrimonio cultural y a la propia región gallega9 ${ }^{9}$.

Todo ello ha supuesto el reconocimiento de la actividad del Consorcio con galardones como el Premio Gubbio 1996, el Premio Europa Nostra 1996, el Premio Europeo de Urbanismo de la Comisión Europea y el Consejo Europeo de Urbanistas al Plan Especial de Protección y Rehabilitación en 1998 -premio que la Unión Europea concede cada cuatro años a una ciudad en reconocimiento por la calidad del trabajo realizado-, el Premio Hábitat del Buenas Prácticas de la ONU 2002 y la Medalla del Eje Atlántico 2003 , entre otros ${ }^{10}$.

8 Disponible en http://www.consorciodesantiago.org

9 Protección y rehabilitación de la ciudad histórica e integración con su entorno natural (Santiago de Compostela, España) 26-06-2002. Disponible en http://habitat.aq.upm.es/bpes/onu02/bp205.html

10 Consorcio de Santiago de Compostela. Disponible en http://www.consorciodesantiago.org 


\subsection{Toledo. A imagen y semejanza de Santiago de Compostela}

Al igual que Santiago de Compostela, en las ciudades castellano-manchegas Patrimonio de la Humanidad, Cuenca y Toledo, se constituyeron estructuras paralelas, aunque no en el tiempo, que parten de la creación de Fundaciones y Reales Patronatos, y que se gestionan en la práctica a través de consorcios. En el caso de Toledo, la Real Fundación, constituida en 1988 con el fin de conservar y revitalizar la ciudad histórica, enfoca sus actividades hacia el estudio, promoción y realización de proyectos urbanísticos, la restauración de bienes culturales, el diseño de planes de investigación y cursos y reuniones, es decir, actividades dirigidas a fomentar la habitabilidad de la ciudad y la protección, estudio y difusión de sus bienes patrimoniales. No tiene un capital fundacional sino que es receptora de fondos fundamentalmente privados. La subvención pública significa un porcentaje muy pequeño del presupuesto anual y, casi siempre, aplicado a un proyecto concreto en el que están involucradas otras entidades. Con esta financiación, la Fundación lleva a cabo diversos proyectos entre los que destacan los relacionados con la reutilización turística del patrimonio cultural urbano, como las colaboraciones con el Programa de Conventos y Monasterios. En 1998 la Real Fundación de Toledo participó de la composición del Real Patronato de la ciudad de Toledo, con el fin de contribuir a fortalecer y potenciar las posibilidades de desarrollo cultural y turístico de la ciudad, con la ayuda de todas las Administraciones Públicas y de instituciones y entidades privadas.

Un año después, en 2001, las Administraciones del Estado, de la Comunidad Autónoma de Castilla-La Mancha, de la Diputación Provincial y del Municipio de Toledo, de común acuerdo, crean el Consorcio de la ciudad de Toledo, ente de gestión del Real Patronato, con carácter público y plena capacidad para obrar. Entre sus fines específicos se encuentra el servir de apoyo administrativo y de gestión al Real Patronato, y el promover y facilitar la coordinación de las competencias de los distintos niveles administrativos. Desde entonces, con la financiación de las cuatro Administraciones, se ha convertido en el principal elemento dinamizador de la actividad rehabilitadora y revitalizadora del Casco Histórico. El Consorcio ha destinado una gran parte de sus recursos a la concesión de subvenciones para la rehabilitación de viviendas, línea de actuación prioritaria ${ }^{11}$.

El Consorcio también está trabajando intensamente en la recuperación de valiosos bienes monumentales, patrimoniales y arqueológicos de la ciudad mediante actuaciones como el plan de color, ordenanza reguladora de publicidad y rotulación, catalogación del arbolado, revisión de catalogación de inmuebles con valor patrimonial, y catalogación de inmuebles en ruinas y/o abandonados en el Casco Histórico. En estos años la inversión del Consorcio ha favorecido la conservación patrimonial de este espacio urbano. Las fachadas de plazas como la de Zocodover, la señalización vial del casco, la eliminación del cableado o la rehabilitación de torres e iglesias son algunos ejemplos.

11 Consorcio Ciudad de Toledo. Disponible en http://consorciotoledo.com/mcomunicacion/memoria.asp. 


\section{REHABILITACIÓN Y REUTILIZACIÓN DEL PATRIMONIO URBANO COMO EXPRESIÓN DE LA NUEVA CAPITALIDAD POLÍTICA}

Desde la década de los 90 comenzaron a ponerse en marcha en los centros históricos de Santiago de Compostela y Toledo políticas urbanas de revitalización tendentes a invertir el proceso de abandono y vaciado de viviendas con la generalización de acciones que conjugaban la regeneración demográfica, la rehabilitación de viviendas y la revitalización económica e inserción funcional.

\subsection{Santiago de Compostela. Nuevos retos y responsabilidades}

En el terreno económico se desarrollan actividades vinculadas fundamentalmente al sector servicios: algunas ya consolidadas, como la universitaria y el comercio, otras que responden a una creciente demanda social como el turismo, la cultura y las derivadas de la administración, que generan a su vez una demanda industrial cualificada de empresas de desarrollo tecnológico. En definitiva, Santiago de Compostela se estructura en cinco pilares: el político-administrativo, como sede de las instituciones del gobierno de Galicia; el educativo, por el peso de la Universidad de Santiago de Compostela; el turístico y cultural, que sostiene el dinamismo de la hostelería y la restauración; el comercial, como cabecera de consumo de una amplia comarca; y el sanitario debido a la importancia del amplio complejo de salud vinculado a la Facultad de Medicina ${ }^{12}$.

\subsubsection{El patrimonio monumental y las nuevas funciones administrativas como expresión de la nueva capitalidad política}

El advenimiento de la democracia asigna a Santiago de Compostela la capitalidad de la Comunidad Autónoma, aprobada en 1982, razón por la que gran parte de los órganos de gobierno y gestión pública tienen su sede en ella, lo que supuso nuevos retos y responsabilidades. Sin embargo, hubo de esperar hasta la aprobación de la ley 4/2002 de 25 de julio para la regulación del Estatuto especial de la ciudad como sede de las instituciones autonómicas y reconocimiento formal como capital de Galicia completando, a nivel normativo, las determinaciones ya contenidas en la ley $1 / 1982^{13}$. En el citado estatuto se establece, entre otras medidas, la necesidad de asignar a Compostela financiación específica en los presupuestos de la Comunidad Autónoma en atención a los "costes de capitalidad", la utilización de Santiago como espacio físico de las instituciones del Gobierno gallego, así como los costes relacionados con la conservación y rehabilitación del patrimonio histórico-monumentales.

En primer lugar, señalar la necesidad que se le planteó a Santiago de Compostela de reservar en su PGOU el espacio para la instalación de nuevos edificios autonómicos, estatales e internacionales (Camarés y Cadaval, 2004). A partir de 1983, las actuaciones

12 Disponible en http://santiagodecompostela.org/facendo_cidade/interior.php?txt=fc_futuro\&lg=cas

13 El Diario Oficial de Galicia (D.O.G.) de 24 de julio de 1.982 recoge la ley $1 / 1.982$ de 24 de junio, reguladora de la Fijación de la Sede de las Instituciones Autonómicas de Galicia. Esta Ley, ya prevista en el artículo 8 del Estatuto de Autonomía, establece el emplazamiento de los edificios de la Xunta y el Parlamento en Santiago de Compostela. 
en el casco se centraron en los edificios administrativos de la Xunta de Galicia en San Caetano, la sede del Parlamento Gallego en el borde del ensanche o la remodelación del Burgo de las Naciones con la construcción del Auditorio de Galicia (Figura 3). De forma paralela hubo de plantearse aspectos relacionados con la accesibilidad y la infraestructura de recepción (Dalda, 2007), consecuencia del cambio de nivel de Santiago de Compostela en la jerarquía urbana y la concentración de funciones centrales en la ciudad (Paris, 2013).

La Presidencia de la Xunta de Galicia tiene su sede oficial en el Palacio de Rajoy, edificio del siglo XVIII situado en la plaza del Obradoiro. Desde su fundación fue casa consistorial, albergue de los confesores que administraban penitencia a los peregrinos y cárcel municipal. Hasta bien entrado el siglo XX continuó sirviendo como residencia de canónigos. El Palacio está ubicado en la parte occidental de la plaza del Obradoiro, frente a la fachada principal de la catedral de Santiago. A su derecha se sitúa el Colegio de San Jerónimo, que hoy sirve de sede del Rectorado de la Universidad de Santiago; a la izquierda el Hospital Real de los Reyes Católicos, en la actualidad Parador de Turismo.

El Parlamento de Galicia tiene su sede en el Palacio del Hórreo desde el año 1989. Anteriormente tuvo dos sedes provisionales: el palacio de Gelmírez y el palacio de Fonseca. El Palacio del Hórreo se comenzó a construir en 1903 con el objetivo de albergar la Escuela de Veterinaria, inaugurándose para tal fin en 1915. Posteriormente se transformaría en cuartel, y en 1986 fue adquirido por la administración regional al Ministerio de Defensa, y tras acometerse las reformas oportunas comenzó a operar como sede del Parlamento gallego el 1 de marzo de 1989 (Figura 4). Las consejerías se encuentran ubicadas en los edificios de San Caetano y San Lázaro.

\subsubsection{Nuevos usos culturales como recursos turísticos}

La riqueza cultural de los centros históricos integra el patrimonio monumental, el urbanístico, la arquitectura popular, el paisaje, los museos, las manifestaciones religiosas, los eventos culturales, la artesanía, los mercados, etc., y aunque se percibe un avance en la valorización e interpretación de este patrimonio como recurso turístico, existen serias dificultades para adecuar los centros históricos a la función turística, incluso en aquellas ciudades donde se han puesto en marcha Planes de Dinamización Turística (PDT) o de Excelencia Turística (PET), caso de las analizadas. La puesta en valor y adecuación del patrimonio cultural como recurso turístico es un proceso complejo y lento que requiere actuar desde el planeamiento urbano, las políticas urbanas, y el PDT (Troitiño, 2003).

Santiago de Compostela es un importante destino cultural, no sólo por su condición de ciudad Patrimonio de la Humanidad sino por ser desde épocas medievales la meta del Camino Jacobeo. El gobierno regional, al comienzo de los años noventa, se planteó la adecuación de la ciudad para dar respuesta a su nueva función de capitalidad, y para las funciones propias de la ciudad como meta del Camino, asociando ambos factores a una política de desarrollo turístico basado en el patrimonio (Precedo, Revilla y Míguez, 2007). En este sentido, posee una imagen internacional consolidada en torno al patrimonio religioso, aunque en los últimos años se aprecia una voluntad por parte de los gestores turísticos de promocionar otras alternativas como el turismo gastronómico, el de congresos y eventos, o el idiomático (Pérez y Lois, 2016). 
Por tanto, el turismo cultural se inserta en las estrategias de promoción de la ciudad, convirtiéndose en uno de los aspectos fundamentales del nuevo marketing urbano (Somoza, 2007), y el planeamiento urbano asume el compromiso cultural con la recuperación de la ciudad histórica, aprovechándose de eventos y conmemoraciones. La experiencia de Santiago se inscribe en el contexto de los proyectos urbanos especiales, relacionados con eventos singulares -en este caso los Años Jubilares y las capitalidades como la capitalidad europea de la cultura en el 2007-que han permitido la movilización de cuantiosos recursos públicos, y la concertación entre las diversas administraciones para convertir la cultura en el principal motor económico y social, reforzando las infraestructuras culturales con la apertura de nuevas galerías de artes y espacios culturales (Estévez, 2001). La celebración en 1993 del Año Jubilar Compostelano, el primero desde la autonomía gallega y desde el ingreso de España en la Comunidad Europea, consolidó la imagen de Compostela como ciudad de encuentro e inició una línea de actuación con continuidad. El compromiso de la Administración Central y de la Autonómica con esta idea permitió consolidar la infraestructura de recepción de la ciudad y consolidar un instrumento de cooperación interadministrativa estable, el Consorcio de la Ciudad, que facilitó la operatividad de la planificación urbanística (Dalda, 2007).

El Consorcio ha desarrollado una intensa labor en la capital gallega. A la ejecución de equipamientos estratégicos como el Palacio de Congresos y Exposiciones de Galicia, hay que unir el Multiusos de Fontes do Sar, la remodelación del Antiguo Banco de España para nueva sede del Museo Nacional de las Peregrinaciones y de Santiago (Figura 5), y las obras de mejora en la Fundación Eugenio Granell, la Fundación Gonzalo Torrente Ballester y el Museo del Pueblo Gallego. En 1987 se recupera el Teatro Principal (del siglo XIX) para espectáculos de artes escénicas, festivales de cine y eventos culturales. En 1989 se inaugura el Auditorio de Galicia, desde 1996 sede de la orquesta Real Filarmónica de Galicia y de la Escuela de Altos Estudios Musicales. En 1993 se pone en marcha el Centro Gallego de Arte Contemporáneo en el límite de la ciudad monumental, en un espacio próximo al convento de Santo Domingo de Bonaval, donde se encuentra el Panteón de Gallegos Ilustres y el Museo del Pueblo Gallego. Paralelamente van surgiendo espacios privados que hacen aportaciones diversificadas a la producción cultural (Estévez, 2001).

La Fundación-Museo Eugenio Granell, con sede en el Pazo de Bendaña (del siglo XVIII) en pleno centro histórico, inicia su andadura en 1995 con una amplísima colección de obras del propio artista, sus colecciones surrealista y étnica, y a partir de 1997 las obras donadas por el artista surrealista Philip West, que también legó su colección de libros surrealistas. La Fundación Torrente Ballester, institución "de interés gallego, de carácter cultural, privado, permanente y sin ánimo de lucro", dotada con biblioteca, auditorio y salas para el archivo del escritor, tiene como objetivo secundario el ser foro cultural que acoja actividades relacionadas con la literatura y otras actividades artísticas, por lo que en su espacio se realizan exposiciones de carácter temporal. El Museo del Pueblo Gallego abrió sus primeras salas en 1976 en el antiguo convento de Santo Domingo de Bonaval. El Centro Abanca, situado en un edificio de finales del siglo XIX, en la Plaza de Cervantes, dispone de tres salas de exposiciones y alberga la primera exposición permanente de arte gallego en Compostela. La Casa del Cabildo, construida en el siglo XVIII en la Plaza de Praterías y ocupada por diferentes 
gremios de artesanos de la ciudad que explotarán comercialmente el bajo del edificio, es desamortizada en 1855 (desamortización de Pascual Madoz) pasando por diferentes manos hasta 2008, año en que el edificio es expropiado por el Consorcio de Santiago y acondicionado para salas de exposiciones o espacios de uso administrativo en 2011.

\section{Figura 3 \\ LOCALIZACIÓN DE ACTUACIONES DE CAMBIO DE USO EN SANTIAGO DE COMPOSTELA}

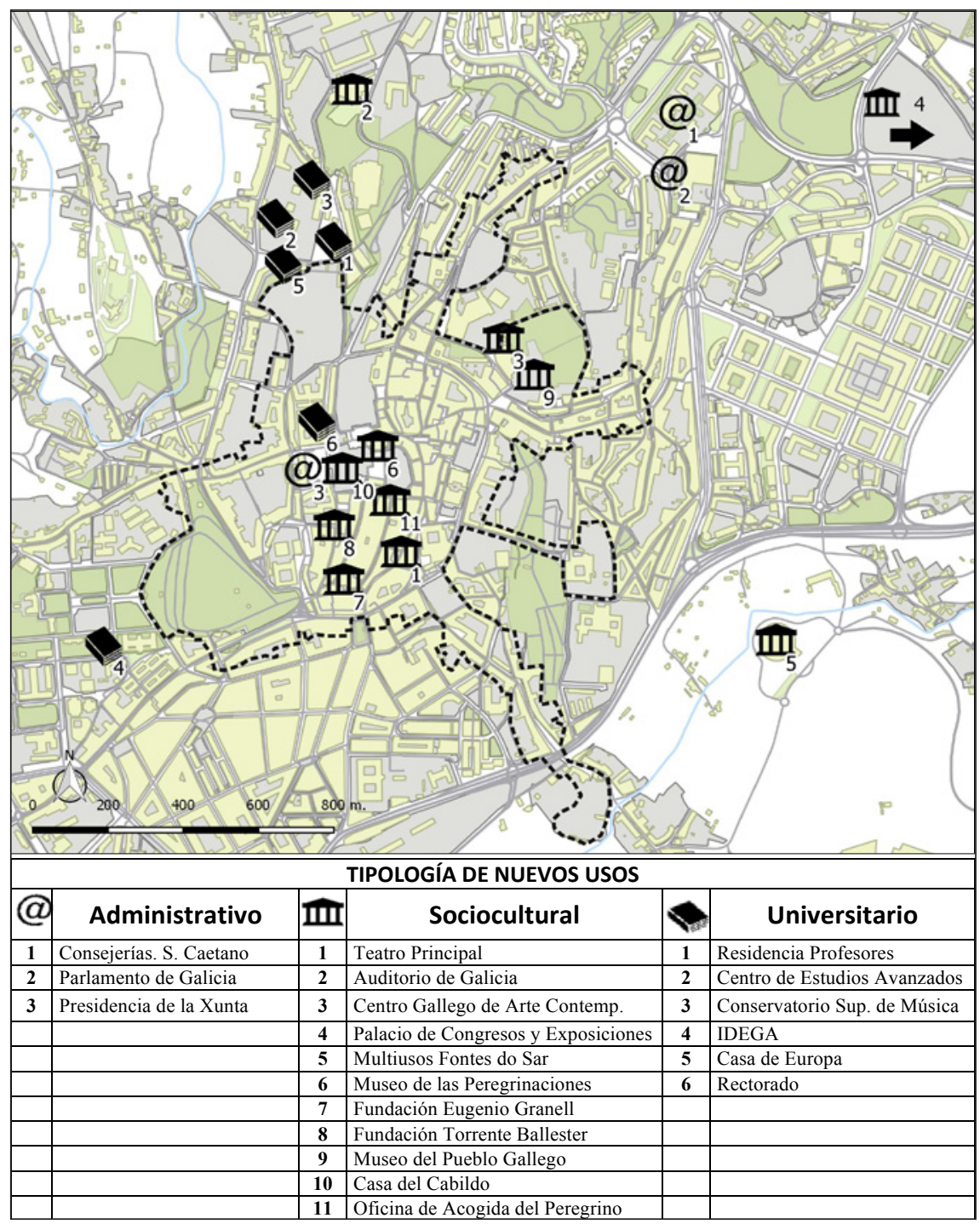

Fuente: IGN. Cartovisual. Elaboración propia. 
Esta actuación fue paralela a la Remodelación del Antiguo Banco de España para su adecuación como sede del Museo Nacional de la Peregrinaciones y de Santiago, situado en la misma Plaza de Praterías. Con estas dos actuaciones el Consorcio recupera y revitaliza uno de los centros neurálgicos de la Ciudad Histórica con dos nuevos equipamientos públicos ${ }^{14}$. La rehabilitación de la Casa de Deán, casa palaciega de mediados del siglo XVIII, actualmente Oficina de Acogida del Peregrino además del lugar donde se recoge la Compostela al finalizar el Camino, es otra de las actuaciones abordadas por el Consorcio.

\section{Figura 4 PARLAMENTO GALLEGO}

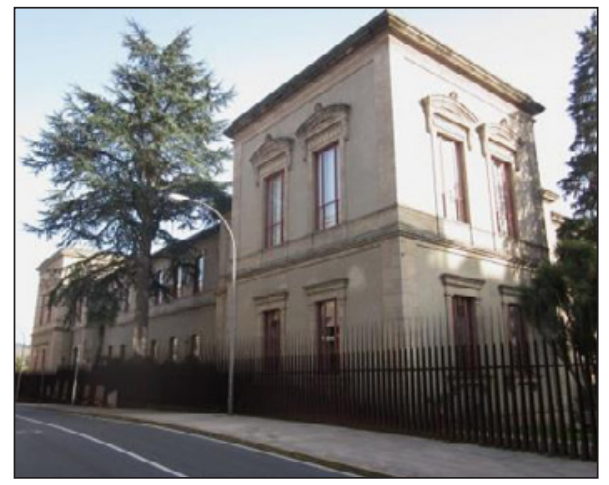

Fuente: Monserrat Villarino

Figura 6 RECTORADO

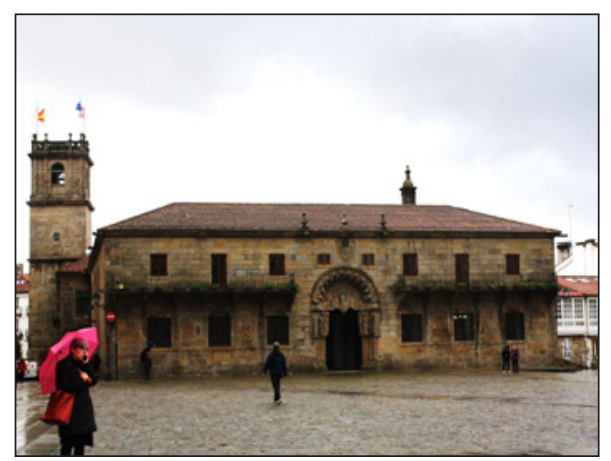

Fuente: Daniel León

\section{Figura 5}

MUSEO DE LAS PEREGRINACIONES

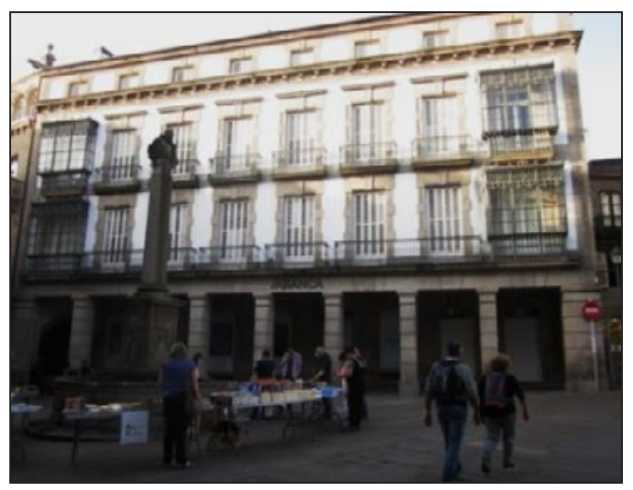

Fuente: Monserrat Villarino

Figura 7

CASA DE EUROPA

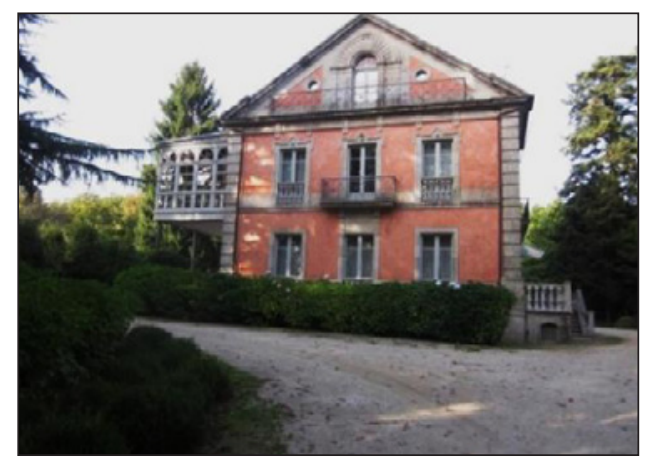

Fuente: Monserrat Villarino

Por todo ello Santiago de Compostela es designada como candidata a la capitalidad europea de la cultura para el año 2000, y la Unión Europea le reconocerá ese título junto

14 http://www.consorciodesantiago.org 
a Aviñón, Bergen, Bolonia, Bruselas, Cracovia, Helsinki, Praga y Reikiavik. Y precisamente en ese año, la Xunta de Galicia acuerda construir una gran Ciudad de la Cultura en la falda del monte Gaiás, según la propuesta ganadora del concurso, firmada por Peter Eisenman, que transformó una parte de la ciudad con el deseo de que surgieran nuevas sinergias económicas (Somoza, 2007).

No es posible entender el significado y alcance económico-espacial de las transformaciones urbanas contemporáneas sin aludir al impacto provocado por el turismo y los efectos inducidos que de él derivan (Manero, 2011). El paisaje se ha convertido en un importante recurso turístico, y en este sentido, la calidad del entorno visual puede justificar en sí misma la afluencia de visitantes. El turista es un gran consumidor de bienes y servicios, su presencia dinamiza los diversos sectores de la actividad económica, genera riqueza y empleo e introduce nuevos hábitos y formas de vida, potencia el desarrollo de las ramas de actividad que cubren directamente las necesidades de consumo de los visitantes e impulsa el desarrollo de otros sectores de actividad. El turismo constituye un pilar importante de la economía de muchas ciudades históricas, habiendo contribuido a la puesta en marcha de procesos de revitalización funcional (Martín, 1998).

El turismo en Santiago de Compostela experimentó un notable incremento a partir de los años 80, pero es 1993 el que marca el inicio de un «boom» que demandaba la creación y adaptación de sus infraestructuras públicas y privadas. La estructura hotelera, que había permanecido prácticamente inmutable entre 1982 y 1993, experimenta desde 1999 un notable impulso cualitativo y cuantitativo, en categoría de los establecimientos y en el número de plazas ofertadas. Al margen de las grandes cadenas hoteleras, han surgido pequeños hoteles, muchos de los cuales se han establecido en el casco histórico, en inmuebles con mayor o menor grado de protección (Muñiz, Freire y Ramos, 2016). Santiago de Compostela ha duplicado y modernizado su planta hotelera y de restauración durante la última década.

A tenor de los datos facilitados por el INE (Encuesta de Ocupación Hotelera ${ }^{15}$ ), las cifras correspondientes al número de viajeros que han entrado en este punto turístico muestra una tendencia al alza. Santiago de Compostela experimenta una afluencia masiva en momentos puntuales (años 1999, 2004 y 2010) coincidentes con la celebración del Año Santo Compostelano, en claro contraste con aquellos en los que no se celebra esta efeméride. No obstante, el número de visitantes prácticamente se ha duplicado entre 1999 y 2017 , pasando de 488.806 a casi 850.000 . En este punto, además del turismo estacional hay que tener en cuenta a los peregrinos que llegan a lo largo de todo el año, a los estudiantes, y a un tipo de visitantes muy cualificado que constituye el turismo cultural, el de congresos y el de empresa.

En el año jubilar de 1999 el fenómeno turístico alcanzó dimensiones problemáticas, lo que obligó al Ayuntamiento, a la Comunidad Autónoma y a la Iglesia, a adoptar medidas ordenadoras, a movilizar importantes recursos y afrontar la toma de decisiones por consenso (Estévez, 2001). En los cascos históricos uno de los impactos más generalizados es la degradación tradicional de la imagen de estos por la propia masificación de la afluencia

15 Disponible en http://www.ine.es/dyngs/INEbase/es/operacion.htm?c=Estadistica_C\&cid=12547361770 $15 \&$ menu $=$ resultados $\& \sec =1254736195376 \&$ idp $=1254735576863$ 
turística, o por la implantación de tipologías inadecuadas en elementos visuales vinculados a la actividad (señalización, mobiliario urbano, publicidad, etc.). Corresponde a las administraciones desarrollar los instrumentos de planeamiento capaces de valorar al paisaje como un recurso turístico básico y velar para que se cumpla con la legislación, en todos los ámbitos de aplicación (Espejo, 2011). Además, la competencia entre las actividades turísticas y las actividades tradicionales puede generar tensiones por el incremento del tráfico y el aumento del número de visitantes (Troitiño, 1995). En definitiva, el turismo es uno de los sectores fundamentales de la economía de Santiago de Compostela, pero también supone riesgos y dificultades, no solo en materia de conservación sino también de puesta en valor y gestión del propio patrimonio (Sotelo, 2012). Para evitar los impactos negativos de la masificación turística se adoptaron medidas como la construcción del área de recepción e información de Juan XXIII, en la que ya era la principal vía de entrada del turismo en el centro (Estévez, 2001).

Además de la propia instrumentalización urbanística, que centra su atención en un modelo multifuncional, la ciudad se ha dotado de una importante instrumentación turística, el PET de Santiago de Compostela, que tiene como objetivo la consecución de un turismo sostenible. Este es un plan de destino que intervino en los elementos básicos de la ciudad con el fin de mejorar su competitividad y provocar un efecto dinamizador en el marco de la sostenibilidad (Espejo, 2008; Santos y Lois, 2005). Los responsables del PET han llevado a cabo un esfuerzo notable y exitoso de mejora de la gestión turística en los últimos años (Varela, 2005). En la ejecución del PET 2000-2005 se abordaron acciones relacionadas con la información y la señalización turística, publicaciones sobre nuevos productos y ofertas turísticas, formación, promoción del turismo religioso y la implantación del Sistema Integral de Calidad Turística Española en Destinos (SICTED), del que la capital gallega es ciudad piloto $^{16}$. Más tarde, el Plan de Mercadotecnia Estratégica de Turismo pretende optimizar los programas de inversión previstos en el mencionado PET, abogando por un turismo de primer orden y nivel internacional mediante la diversificación y enriquecimiento de la oferta turística, desestacionalizando la oferta y la demanda (Santos y Lois, 2005).

\subsubsection{Una función universitaria con proyección internacional}

La Universidad de Santiago de Compostela, con sus más de 500 años, ha continuado su crecimiento en las últimas décadas. De hecho Santiago es una ciudad que cuenta con un total de 96.456 habitantes (INE, 2017), y de ellos aproximadamente la tercera parte son estudiantes universitarios. En la actualidad, entre sus dos campus -Santiago y Lugo- dispone de casi treinta centros, cerca de ochenta departamentos y más de sesenta titulaciones, además de numerosas instalaciones como los institutos de investigación, residencias universitarias, instalaciones deportivas o culturales, bibliotecas, etc. Con un enorme patrimonio, ofrece sedes idóneas para todo tipo de acontecimientos. Desde edificios emblemáticos

16 El Ayuntamiento de Santiago señala que el Plan de Excelencia Turística "cumplió sus objetivos" Actualidad 24 horas. Actualidad empresarial en España. Periódico 26/10/2005. Disponible en http://www. actualidad24horas.com/el-ayuntamiento-de-santiago-senala-que-el-plan-de-excelencia-turistica-cumplio-sus objetivos/5908/ 
e históricos como los colegios de Fonseca -edificio del siglo XVI, sede de la universidad compostelana en sus inicios y actualmente Biblioteca General de la Universidad- y el Colegio de San Jerónimo -edificio del siglo XVII situado en la Plaza del Obradoiro, actual sede del Rectorado (Figura 6)-, al gran paraninfo de la Facultad de Geografía e Historia del siglo XVIII, y al monasterio de San Martín Pinario - monasterio benedictino del siglo $X$, actualmente sede de la Escuela Universitaria de Trabajo Social, del Instituto Teológico Compostelano, del Seminario Mayor y del Archivo Histórico Diocesano-, hasta construcciones tan actuales como la Facultad de Ciencias de la Comunicación.

Otros ejemplos de intervenciones en edificios para la universidad son los realizados en la Finca Simeón, más conocida como Finca Vista Alegre, por el paisaje de la ciudad histórica y las vistas de sus propios jardines. La actuación consistió en la reconversión de la finca en parque público y de la villa familiar, palacete con influencia "caribeña" o "colonial" erigido como residencia de una familia de la burguesía en 1903, en Residencia para Profesores Invitados. Su entorno ajardinado es característico de los pazos gallegos, de inspiración barroca. Disponer de una residencia con historia para los participantes en actividades académicas era uno de los objetivos de la Universidad con el fin de reforzar la proyección internacional de la misma. La finca también acoge edificios cedidos en uso a la Universidad de Santiago de Compostela a través del Consorcio, con motivo de la celebración del 500 aniversario de la universidad compostelana: cuatros nuevos volúmenes edificatorios destinados a Centro de Estudios Avanzados, Conservatorio Superior de Música, Instituto para el Desarrollo de Galicia y Documentación Europea (IDEGA) y un edificio residencial también de carácter universitario. Entre 1998 y 2000 se urbaniza la finca y se rehabilita la villa, que pasan a denominarse Parque Público Municipal Vista Alegre y Casa de Europa (Figura 7) respectivamente. La conversión de propiedad privada en patrimonio público ha permitido recuperar una de las parcelas más valiosas del centro de Compostela ${ }^{17}$.

\subsubsection{Uso residencial, espacios libres y accesibilidad}

Las acciones de rehabilitación residencial del Consorcio se dirigieron prioritariamente a estabilizar la población residente, respondiendo a sus aspiraciones de mejora de la vivienda. La rehabilitación ligera y los procedimientos de gestión pública basados en la proximidad a los usuarios, fundamentan una estrategia difusa basada en la iniciativa privada que es la que activa los mecanismos públicos de fomento.

De forma paralela se duplicó la dotación de parques públicos con la adquisición y acondicionamiento de 18 hectáreas de zonas verdes y se han consolidado dos corredores verdes que incluyen la recuperación de cauces públicos, arbolado y vegetación, jardines históricos y elementos etnográficos ${ }^{18}$. En el primer corredor, en torno al centro histórico, con la ordenación de más de un millón de metros cuadrados de superficie, se han creado

17 Universidad Santiago de Compostela. Casa Europa. Disponible en http://www.usc.es/es/servizos/ casaeuropa/

18 Protección y rehabilitación de la ciudad histórica e integración con su entorno natural (Santiago de Compostela, España) 26-06-2002. Disponible en http://habitat.aq.upm.es/bpes/onu02/bp205.html 
2.300 plazas de estacionamiento, destacando el aparcamiento de Juan XXIII, a 150 metros de la Catedral, junto a la estación de autobuses. En el segundo anillo se han creado 2.400 plazas. Y en tercer lugar, sobre las principales vías de acceso, se ha construido una red periférica de aparcamientos que supera en número de plazas la suma de los dos anteriores, comunicados con el centro mediante líneas de transporte público (Estévez, 2001). Además, en el oeste se ha abordado la creación de parques que unen los campus universitarios, en contacto con el paisaje rural, y en el este parques que unen los barrios populares próximos al Camino de Santiago. A la construcción de estacionamientos públicos en su entorno, hay que unir el proceso de peatonalización del recinto intramuros ${ }^{19}$.

\subsection{Toledo. Renovación y recuperación urbana}

De forma paralela Toledo se convierte en capital de Castilla-La Mancha en 1982, actuando esta circunstancia como palanca de renovación, de recuperación urbana y de crecimiento (Campos, 2002). Además, se cumple así, finalmente, esa histórica aspiración de volver a ser capital. Adquiere entonces la ciudad un nuevo ritmo de vida y una mayor vitalidad en aspectos económicos y culturales, lo que sirvió como trampolín para un nuevo periodo de crecimiento y desarrollo (Ganau, 2003). Y a medida que la ciudad crece y su población aumenta se percibe en ella un espíritu más abierto que en unos años llega a transformar la ciudad provinciana en una nueva capital que afronta el futuro con el mejor de sus espíritus de modernidad y progreso ${ }^{20}$.

La reutilización de edificios singulares sin apenas uso para nuevas funciones, preferentemente culturales, administrativas y educativas, permite la rehabilitación y conservación de estos edificios y la presencia de actividad en su entorno con todos los aspectos positivos que ello conlleva.

\subsubsection{Nuevos usos administrativos consecuencia de la capitalidad}

A mediados de la década de los 80 empiezan a generalizarse procesos de recuperación de viejos contenedores infrautilizados cuyo objetivo es la ubicación en ellos de nuevos usos administrativos relacionados con la nueva situación de Toledo como capital de la nueva región castellano-manchega. Ante la necesidad de edificios para acoger los distintos organismos regionales se optó, en consonancia con el urbanismo de recuperación de la época, por abordar distintos procesos de rehabilitación en edificios histórico-artísticos del casco histórico que se encontraban en una lamentable situación para darles un nuevo uso. En esta línea de actuación se han llevado a cabo importantes actuaciones de rehabilitación de edificios singulares que ahora sirven como dependencias de sus propios servicios (sede de la Presidencia de la Junta de Comunidades, Cortes de Castilla-La Mancha, consejerías diversas y delegaciones provinciales). Algunos ejemplos de intervenciones para usos administrativos son las realizadas en el Palacio de Fuensalida, Convento de San Gil,

19 Disponible en http://santiagodecompostela.org/facendo_cidade/facendo.php?txt=fc_pxom\&lg=cas

20 Disponible en http://www.eldigitalcastillalamancha.es/la-capitalidad-de-castillala-mancha-no-es-tanrentable-para-oledo $-91315 . \mathrm{htm}$ 
Hospital del Nuncio, Colegio de Doncellas y Convento de Santo Domingo el Real, entre otros. El edificio de San Gil, del siglo XVII, para sede de las Cortes de Castilla-La Mancha desde 1986 (Figura 8) y el Palacio de Fuensalida, del siglo XV, para sede de la Presidencia de la Junta de Comunidades de Castilla-La Mancha desde 1983 (Figura 9). San Gil es un edificio que asume con gran dignidad su papel de símbolo autonómico constituyendo, junto con el escudo y la bandera de la Región, una de las señas de identidad de CastillaLa Mancha. El Palacio de Fuensalida renace con una nueva imagen, convirtiéndose en un espacio de representación de la Comunidad Autónoma y un espacio cultural para los castellano-manchegos ${ }^{21}$. El Hospital del Nuncio, del siglo XVIII, para sede de la Consejería de Economía y Hacienda. Y el Colegio de Doncellas, del siglo XVI, para residencia universitaria.

Según el estudio efectuado por los investigadores de la Universidad de Barcelona, Bosch, Espasa y Montolio (2010) para determinar los costes de capitalidad y centralidad de las ciudades españolas de más de 75.000 habitantes, estos responden principalmente a la presencia de instituciones del gobierno autonómico y estatal, suponiendo una pérdida de ingresos por sustitución de actividad, porque algunos recursos escasos, como el suelo, se usan para instalaciones administrativas en lugar de otras actividades comerciales, y en el primero de los casos, el municipio no percibe la recaudación por el IBI, entre otros impuestos.

Figura 8

\section{CORTES DE CASTILLA-LA MANCHA}

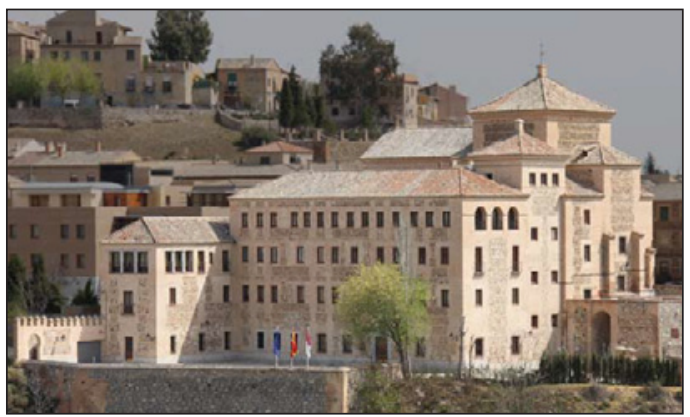

Fuente: Calvo, 2008.

\section{Figura 9 \\ PRESIDENCIA}

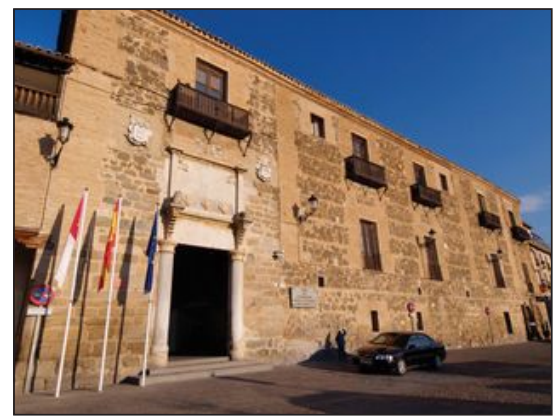

Fuente: Barros, lacerca.com

\subsubsection{Nuevos usos culturales. El patrimonio cultural como activo económico}

La rehabilitación integral de la ciudad histórica solo es posible mediante la recuperación de todas las funciones urbanas, de ahí la importancia de funciones como la administrativa, universitaria, sociocultural y turística, aparte de la residencial. Como sede de instituciones culturales resaltar la presencia de Archivos Históricos, instalaciones de la Universidad e institutos de investigación, entre otras instalaciones.

21 Palacio de Fuensalida: De la Aristocracia a la Democracia. Dossier de prensa. Disponible en www. jccm.es/.../Dossier\%20de1\%20Palacio\%20de\%20Fuensalida.pdf 
Para usos culturales pueden citarse los ejemplos de intervenciones en el Convento de Jesús y María, Sinagoga del Tránsito, Mezquita de Tornerías, Hospital de Tavera, Casa Museo del Greco, Convento de Santa Fe y El Alcázar (Campos, 1991) (Figura 10). El Convento de Jesús y María, del siglo XVII, fue adquirido en 1984 por el Ministerio de Cultura, después de que las monjas dominicas se trasladaran a otro convento más moderno, para instalar en él la sede del Archivo Histórico Provincial de Toledo. La Sinagoga del Tránsito, del siglo XIV, para sede del Museo Sefardí. La Mezquita de Tornerías, del siglo XI y asentada sobre cimientos romanos, para albergar la Fundación Centro de Promoción de la Artesanía. El Hospital de Tavera, del siglo XVI, para Museo Fundación Lerma (con parte de las colecciones artísticas de dicho linaje: cuadros de El Greco, Ribera, Tintoretto, Tiziano, Jacopo Bassano, y Zurbarán, entre otros), la Sección Nobleza del Archivo Histórico Nacional desde 1993, y el Archivo Histórico de la Nobleza desde 2017. El Hospital de Santa Cruz, del siglo XVI, para Museo de Santa Cruz (Figura 11). El Alcázar, del siglo XVI, sede de la Biblioteca de Castilla-La Mancha desde 1998 en la planta superior, y a partir de 2010 para sede del Museo del Ejército en las restantes dependencias. El convento de Santo Domingo el Real, del siglo XIV, para convento de clausura y Archivo Histórico Conventual. Y el Museo del Greco, que tras varias reformas en los dos edificios que lo constituyen, uno del siglo XVI y otro de principios del siglo XX, vuelve a abrir sus puertas en 2011 .

\subsubsection{La función turística. Una estrategia de desarrollo turístico basada en el patrimonio}

La proximidad a Madrid, la mejora de las comunicaciones y la consideración del patrimonio cultural como un activo económico han impulsado el desarrollo del turismo en Toledo y la ampliación de la infraestructura de acogida.

La excesiva presión turística sobre determinados lugares origina problemas de conservación (Zárate, 2008). Las principales propuestas del PET de Toledo se centran en el impulso de un proceso de cambio para modificar de forma positiva y significativa la situación actual del turismo en la ciudad de Toledo, y el establecimiento de líneas estratégicas que proyecten el desarrollo sostenible de la ciudad situándola como destino líder del turismo cultural, tanto en el mercado nacional como el internacional. Las actuaciones que contempla tienen como objetivo el aumento de la calidad de los servicios turísticos del destino, la mejora del medio urbano y natural del municipio, la ampliación y mejora de los espacios de uso público, la mejora de los servicios públicos, la diversificación y mejora de la oferta complementaria, la puesta en valor de recursos turísticos, la creación de nuevos productos y la sensibilización e implicación de la población y agentes sociales en una cultura de la calidad ${ }^{22}$.

Al igual que en Santiago de Compostela, se ideó una estrategia conocida como Toledo 21 para una ciudad que se consideraba destino turístico maduro, que pretendía profesionalizar el sector, potenciarlo, diversificarlo, cualificarlo y reorganizarlo, apartándose de

22 JCCM Plan de Excelencia Turística de Toledo. Toledo como destino líder del turismo cultural. 18/11/2000. Disponible en http://www.castillalamancha.es/actualidad/notasdeprensa/plan-de-excelenciatur\%C3\%ADstica-de-toledo-toledo-como-destino-1\%C3\%ADder-del-turismo-cultural 
planteamientos sectoriales e integrando la estrategia turística en el conjunto de las políticas urbanas. Esta estrategia no tuvo éxito por las dificultades surgidas ante la necesidad de concertación, además de por falta de liderazgo de las instituciones. Según Santos y Lois (2005), no se debería haber planteado el turismo como una actividad central sino como parte de un marco plural y multifuncional.

\section{Figura 10 \\ LOCALIZACIÓN DE ACTUACIONES DE CAMBIO DE USO EN TOLEDO}

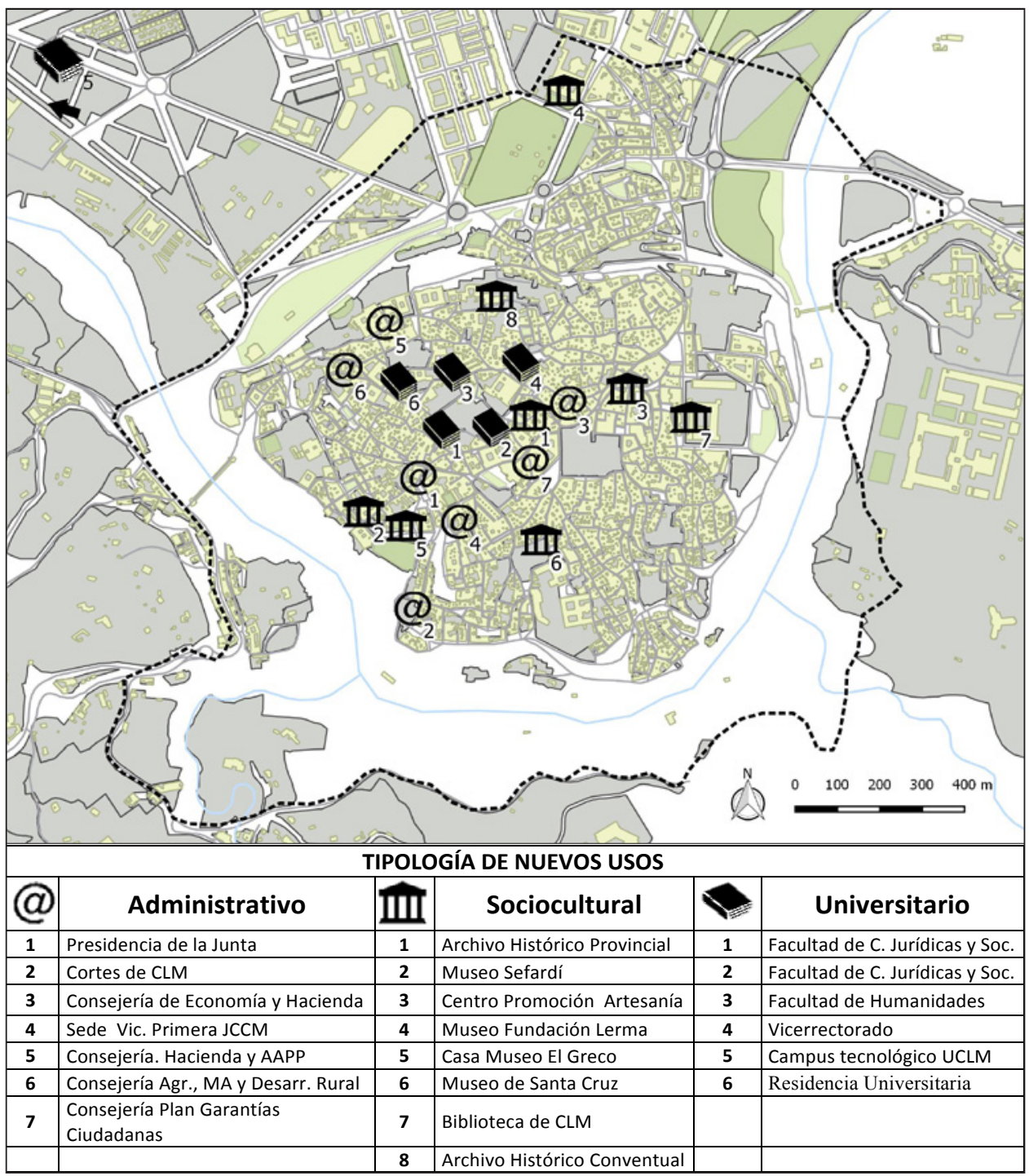

Fuente: IGN. Cartovisual. Elaboración propia. 
En cuanto a la presencia de turistas en la ciudad, y teniendo en cuenta los datos de la Encuesta de ocupación hotelera del $\mathrm{INE}^{23}$, el número de viajeros que han entrado en la ciudad de Toledo registra una tendencia al alza más uniforme que Santiago de Compostela en los últimos años, aunque experimentó un aumento importante coincidiendo con la celebración del Año del Greco en 2014. En cualquier caso, en los últimos veinte años prácticamente se ha duplicado el número de visitantes, como en la ciudad gallega, pasando de los casi 370.000 viajeros a los 618.653 que registra para el año 2017.

\subsubsection{Nuevos usos educativos. Una universidad joven y multicampus}

En cuanto a los usos educativos en el casco histórico, la Universidad de Castilla-la Mancha, fundada mediante la Ley de 30 de junio de 1982, fue hecha efectiva en 1985. Su implantación representó la vocación de la comunidad Autónoma por dotarse de un sistema universitario propio, al servicio de más de millón y medio de ciudadanos asentados en los $80.000 \mathrm{~km}^{2}$ mediante la estructuración de cuatro campus universitarios en Albacete, Ciudad Real, Cuenca y Toledo, y enseñanzas en las localidades de Almadén y Talavera de la Reina. El campus de Guadalajara está adscrito a la Universidad de Alcalá de Henares. El número de alumnos matriculados ha ido creciendo de manera espectacular, y este crecimiento ha impulsado un aumento del empleo en el sector servicios y ha contribuido a retener la población universitaria en la región al contener la tradicional emigración de adultos jóvenes durante las décadas anteriores (Vázquez y Aparicio, 2007).

En Toledo, la función universitaria ha impulsado procesos de recuperación urbana, aunque en menor medida que en otras ciudades (Campos, 2002). La Facultad de Ciencias Jurídicas y Sociales tiene su sede en el antiguo Convento de San Pedro Mártir (siglo XV) y en el antiguo Convento de Madre de Dios; la Facultad de Humanidades en el Palacio de Padilla (siglo XV); el Vicerrectorado del Campus, además del Centro de Estudios de Postgrado, Centro de Estudios Europeos y Centro de Estudios de Derecho del Consumo en el Palacio del Cardenal Lorenzana (siglo XVIII) (Figura 12); y el Campus Tecnológico (Facultades de Ciencias del Deporte, Ciencias del Medio Ambiente, Enfermería, Fisioterapia, Educación e Ingeniería Técnica Industrial) en la Antigua Fábrica de Armas de Toledo (siglo XVIII).

El Convento de San Pedro Mártir, del siglo XVI, viene funcionando desde 1969 como sede universitaria, primero como colegio universitario adscrito a la Universidad Complutense, y desde 1991 como la Facultad de Ciencias Jurídicas y Sociales. El Convento de la Madre de Dios, fundado en 1482, tras varias restauraciones parciales durante el siglo XX, se adquiere por la Universidad de Castilla-La Mancha y entre 2002 y 2005 se produce la rehabilitación definitiva para complemento del centro universitario de San Pedro Mártir y sus espacios administrativos. Hoy día, forma parte de las dependencias de la Facultad de Ciencias Jurídicas y Sociales.

La renovación y recuperación del conjunto de la Fábrica de Armas, Real Fábrica de Espadas a orillas del río Tajo, diseñado por Sabatini en tiempos de Carlos III (siglo XVIII), se caracteriza por presentar uno de los conjuntos mejor conservados y de mayor calidad de

23 Disponible en http://www.ine.es/dyngs/INEbase/es/operacion.htm?c=Estadistica_C\&cid=12547361770 $15 \&$ menu $=$ resultados $\& \sec =1254736195376 \&$ idp $=1254735576863$ 
la arquitectura industrial realizada en España en los dos últimos siglos. En 1998 el Ministerio de Defensa vende al Ayuntamiento de Toledo los terrenos y edificios de la Fábrica de Armas y este a su vez cede el uso a la Universidad de Castilla-La Mancha, la cual creó en esta zona de la ciudad el Campus Universitario Tecnológico de Toledo. Las actuales instalaciones universitarias ocupan más de una docena de los edificios restaurados y rehabilitados de la antigua Fábrica de Armas. Pero de todos ellos, resalta el Edificio Sabatini. Sus pabellones albergan hoy día laboratorios de docencia e investigación, aulas, seminarios, oficinas universitarias, bibliotecas y zonas deportivas para la actividad docente universitaria. Su ocupación en 1998 por parte de la Universidad de Castilla-La Mancha supuso un símbolo de progreso y desarrollo para la ciudad de Toledo tras su definitivo cierre en 1966.

Figura 11

MUSEO SANTA CRUZ

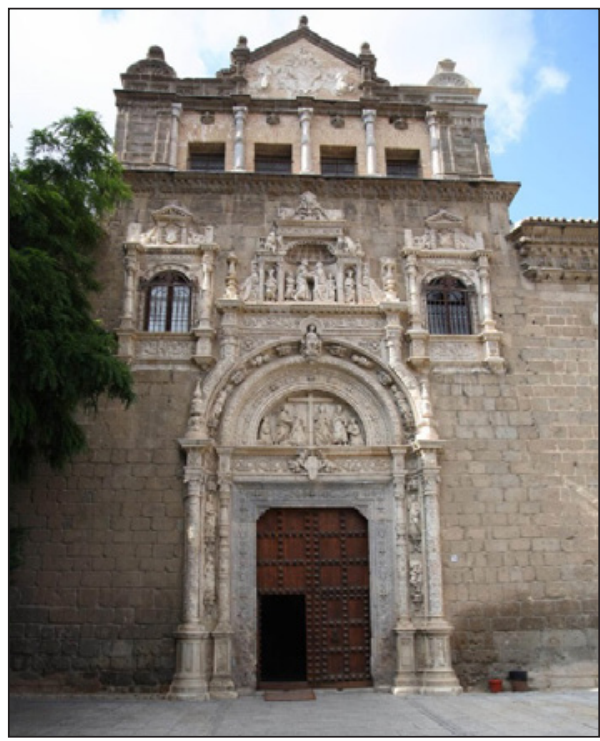

Fuente: http://www.encastillalamancha.es
Figura 12 VICERRECTORADO

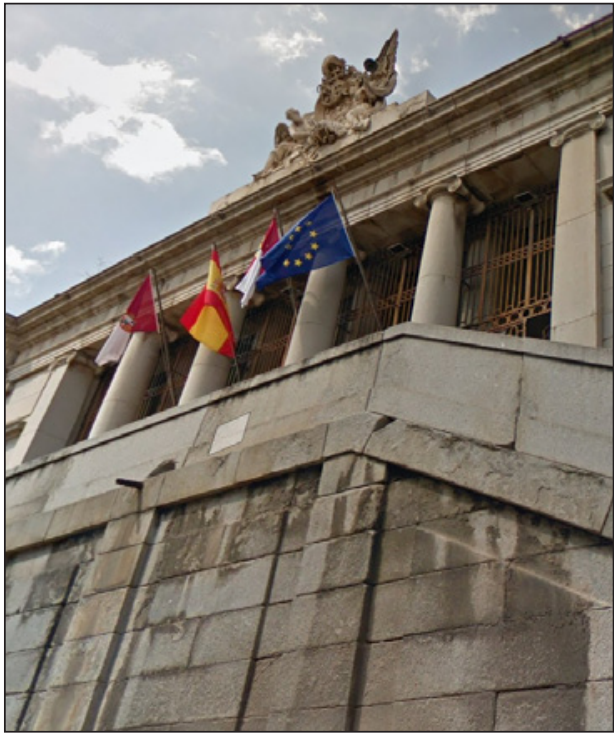

Fuente: Google Earth (marzo, 2018)

\subsubsection{El uso residencial. Factor clave en la recuperación funcional}

La recuperación urbana presta especial atención a dos problemas relevantes en las ciudades históricas contemporáneas: la preservación de los usos residenciales con la mejora de las condiciones de las viviendas, y la regeneración ambiental de los espacios libres marginados ${ }^{24}$. En la pervivencia de la multifuncionalidad tiene un papel decisivo la función residencial, al ser garantía de heterogeneidad social, pero la recuperación urbana,

24 Protección y rehabilitación de la ciudad histórica e integración con su entorno natural (Santiago de Compostela, España) 26-06-2002. Disponible en http://habitat.aq.upm.es/bpes/onu02/bp205.html 
si no tiene las pertinentes cautelas, puede provocar un encarecimiento del precio de suelo y hacer difícil la permanencia o la entrada de familias de rentas medias o bajas, tal como está ocurriendo ya en Santiago de Compostela (Troitiño, 2003).

Ante la pérdida de población del casco histórico, las alternativas y soluciones al problema se recogieron en el Plan Especial, en el que se plantea la recuperación integral de la ciudad, y la puesta en marcha de actuaciones como Toledo a Plena Luz, programa regional que potenciaba la rehabilitación de viviendas, el control del tráfico, y la mejora de los equipamientos urbanos sanitarios y docentes, entre otros (Santos y Lois, 2005). La elevada proporción de viviendas vacías supone una reserva de suelo residencial que podría cubrir parcialmente las necesidades de vivienda de los toledanos y atraer a una parte del crecimiento de población estimado para el conjunto de la aglomeración. Para ello habría que gestionar adecuadamente las posibilidades del parque residencial, desarrollar los programas de rehabilitación previstos por el Plan Especial y profundizar en las ayudas concedidas por el Consorcio y la Junta de Comunidades de Castilla-La Mancha (Campos, 1991).

Entre las intervenciones realizadas, destacan las orientadas a impulsar la recuperación de edificios de uso residencial mediante subvenciones extraordinarias. Sus beneficiarios son los promotores de actuaciones de rehabilitación y nueva construcción de viviendas destinadas a residencia habitual o promotores de rehabilitación de fachadas de locales comerciales. La conservación de la edificación anterior -reforma y rehabilitación- ha ido ganando terreno frente a las obras de nueva planta, con o sin demolición. Las obras mayores ofrecen una distribución periférica, dejando el corazón del casco histórico casi sin intervenciones en los últimos 30 años, apreciándose una cierta tendencia hacia la transformación en los sectores más accesibles en vehículo, así como en barrios de menor índice de renta (Busquets, 2000).

\section{CONCLUSIONES}

El establecimiento de las capitalidades de Galicia y Castilla-La Mancha en Santiago de Compostela y Toledo respectivamente, junto con las políticas urbanas destinadas a proteger, renovar, recuperar o revitalizar sus centros históricos, ha producido una importante recuperación física del patrimonio y cambios funcionales. Todo ello ha dado lugar a que las políticas conservacionistas hayan sido avaladas por la UNESCO con el reconocimiento de sus centros históricos como Patrimonio de la Humanidad.

El planeamiento urbanístico, pieza clave de las políticas de recuperación, al permitir crear el marco adecuado para abordar globalmente los problemas relacionados con la protección y con la recuperación, ha tenido y está teniendo ciertas dificultades ante la prioridad asignada a las dimensiones físicas frente a las dimensiones sociales y funcionales, la falta de recursos, y la limitada capacidad de gestión de muchos ayuntamientos. No obstante, este no es el caso de las ciudades analizadas ya que en ambas la existencia de un consorcio ha favorecido la cooperación interadministrativa estable, lo que ha provocado sinergias derivadas de la coordinación permitiendo diseñar estrategias de futuro y consolidar alianzas que supongan la utilización del patrimonio cultural urbano como motor de un desarrollo. En el caso de Santiago de Compostela, la recuperación urbana 
se ha consolidado gracias a la existencia de un foro de coordinación administrativa y cooperación institucional, el compromiso político municipal con un proyecto cultural de ciudad, la existencia de adecuados instrumentos urbanísticos, la progresiva implicación de los ciudadanos y una estrategia de equilibro entre pasado y presente (Troitiño, 2003). En el caso de Toledo, el Consorcio se ha convertido en el principal elemento dinamizador de la actividad rehabilitadora y revitalizadora, siendo la referencia en todo lo relacionado con la puesta en valor del patrimonio toledano, tanto monumental como residencial.

La consideración del patrimonio cultural como un activo económico abre nuevas expectativas a la hora de abordar las relaciones entre administración, cultura, universidad y turismo. La recuperación y reutilización del patrimonio cultural, con la asignación de nuevos usos a viejos contenedores, en definitiva, la apuesta por la multifuncionalidad en los centros históricos, requiere por un lado, aprovechar las oportunidades de funciones como la administrativa y la educativa, o de emergentes como la turística y la cultural, y por otro, introducir innovaciones en el terreno de la gestión.

Tras analizar la distribución espacial de los nuevos usos en la ciudad de Santiago de Compostela, es evidente que la mayoría de los culturales se concentran en su centro histórico, mientras las funciones universitarias y administrativas, surgidas al amparo de la capitalidad autonómica durante los últimos treinta y cinco años, se localizan en el borde del ensanche. En el caso de las funciones educativas, esta disposición puede justificarse por la presencia de una universidad con más de 500 años de antigüedad instalada en edificios del centro histórico (Campus Histórico), y la necesidad de espacio cuando se plantea la construcción de los otros dos campus universitarios, ubicándolos en zonas exteriores al casco urbano: el Campus Norte y el Campus Vida, en la fachada norte y poniente de la ciudad, respectivamente. En el caso de las funciones administrativas, la distribución en el tejido urbano externo al centro histórico se debe a la necesidad de amplios espacios para ubicar en ellos los nuevos servicios de la recién creada Xunta de Galicia a través de sus consejerías.

En contraposición, en el centro histórico de Toledo la polarización y diversidad de nuevos funciones en edificios históricos es más que notoria, concentrando este espacio la mayor parte de las intervenciones de cambio de uso desde el establecimiento del Estado de las Autonomías. Y esto ha sido posible por el menor dinamismo de este espacio urbano en el momento de establecerse la capitalidad, y por la existencia de un porcentaje elevado de antiguos contenedores infrautilizados o en desuso que podían ser reutilizados, tras su rehabilitación, para facultades, bibliotecas y laboratorios de su recién creada universidad, para archivos, bibliotecas y museos, o para instalaciones de la Junta de Comunidades de CastillaLa Mancha. No obstante, ante la necesidad de nuevas instalaciones, aquí también surge otro campus extramuros con la renovación y recuperación del conjunto de la Fábrica de Armas.

Además de la propia instrumentalización urbanística, que centra su atención en un modelo multifuncional, y que está consiguiendo que los centros históricos continúen representando una importante centralidad simbólica y funcional, la ciudad se ha dotado de una importante instrumentación turística, que tiene como objetivo la consecución de un turismo sostenible. Pero el desarrollo del turismo también tiene su lado oscuro, pues cuando la economía depende en exceso de esta actividad se expone a serios peligros y a una disminución de la afluencia de visitantes. En el caso de Santiago, ciudad sometida 
a una gran presión de entradas diarias en ella, sólo el aprovechamiento consciente y sostenible de dichos recursos hará posible que la ciudad continúe siendo eminentemente humana (Monterroso, 2007) minimizando al máximo los impactos negativos producidos por el turismo y maximizando sus ventajas. En Toledo, en los últimos veinte años prácticamente se ha duplicado el número de visitantes, como en la ciudad gallega. La cercanía de Madrid, el Tren de Alta Velocidad y la consideración del patrimonio cultural como un activo económico han impulsado el desarrollo del turismo en Toledo y la ampliación de la infraestructura de acogida, pero la proliferación de alojamientos turísticos en el centro histórico está intensificando la pérdida de población.

La vivienda continúa siendo uno de los problemas pendientes, pues la rehabilitación, incluso cuando existe cooperación entre administraciones, tiene muchas complicaciones para generar procesos de recualificación, sobre todo en los barrios peor posicionados desde el punto de vista socioeconómico. Además, hay que tener cuidado porque la renovación urbana puede provocar un encarecimiento del precio de suelo, hacer difícil la permanencia o la entrada de familias de rentas medias o bajas, y potenciar la expulsión demográfica.

La relación de la ciudad histórica con el medio natural circundante ha sido un elemento básico en el diseño y redacción de los planes especiales de ambas ciudades. En el caso de Toledo mediante el mantenimiento de las vegas como espacios no urbanizables y la exigencia de un estudio de impacto ambiental previo a la construcción de nuevas infraestructuras urbanas. En Santiago mediante la planificación urbanística de la ciudad, la integración ambiental, y el respeto al medio ambiente, lo que ha provocado la distinción del Plan Especial de Protección y Rehabilitación como Buena Práctica en el Concurso de Buenas Prácticas de Hábitat 2002, siendo catalogada como AWARD. En definitiva, en ambas ciudades se ha producido la integración con su entorno natural y se han recuperado para el uso peatonal los centros históricos aunque, según Almarcha et al. (2011), en el caso de Toledo la llegada del Tren de Alta Velocidad y el acceso desde la carretera de Ocaña han impactado negativamente en el paisaje de la ciudad.

Para concluir, tanto en Santiago de Compostela como en Toledo, los centros históricos han experimentado profundos cambios funcionales, $\mathrm{y}$ aun aceptando que todavía falta mucho por hacer, hay que reconocer que se ha hecho un esfuerzo importante y que la situación de ambos es mucho más favorable que la existente a comienzos de la década de los ochenta. En conjunto, pues, las estrategias cultural-turística y universitaria, junto a las relacionadas con los servicios administrativos propios de una capital autonómica, permiten a ambas ciudades disfrutar de una excelente perspectiva de futuro.

\section{BIBLIOGRAFÍA}

ALMARCHA, E., DÍEZ DE BALDEÓN, P., PERIS, D. y SÁNCHEZ, I. (2011): Paisajes de los Conjuntos Históricos de Castilla-La Mancha. Ciudad Real. Centro de Estudios de Castilla-La Mancha. Junta de Comunidades de Castilla-La Mancha. Colección Coediciones. Ediciones de la Universidad de Castilla-La Mancha, 364 pp.

ÁlVAREZ, I. (2017): La evolución urbana de Toledo. Grupo de Ciudades Patrimonio de la Humanidad. Comisión de Ciudad y Patrimonio. 
APARICIO, A.E. (2004): “A Plena Luz y la revitalización del Casco Antiguo de Cuenca”. Nimbus. Revista de Climatología, Meteorología y Paisaje, n 13-14, pp. 71-86.

BOSCH, N., ESPASA, M. y MONTOLIO, D. (2010): Estimación de los costes de centralidad y capitalidad de las grandes ciudades españolas. Barcelona, Universitat de Barcelona e IEB Versión preliminar.

BUSQUETS, J. (2000): Toledo y su futuro. El Plan Especial del Casco histórico de Toledo. Madrid, Ayuntamiento de Toledo, Caja de Castilla-La Mancha, Empresa Municipal de la Vivienda de Toledo, S.A., 388 pp.

CALVO, M. (Coord.) (2008): Historia y Arte del Convento de San Gil. Cortes de CastillaLa Mancha. Toledo, Cortes de Castilla-La Mancha, 125 pp.

CAMARÉS, L. y CADAVAL, M. (2004): "Costes de capitalidad. Estudio de un caso: Santiago de Compostela”, en XI Encuentro de Economía Pública: los retos de la descentralización fiscal ante la globalización, noviembre de 2004. Barcelona.

CAMPOS, M.L. (1991): “Toledo a Plena Luz. Un programa de rehabilitación”. Anales de Geografía de la Universidad Complutense, no 11, pp. 217-223.

CAMPOS, M.L. (2002): “Análisis del turismo en Castilla-La Mancha en el umbral del nuevo milenio", en CAMPOS, M.L. (Coord.) El turismo en Castilla-La Mancha: análisis y prospectiva. Cuenca, Ediciones de la Universidad de Castilla-La Mancha, pp. 69-102.

CAMPOS, L. y RODRÍGUEZ, M.A. (2009): "El poblado obrero. Vestigios de un urbanismo socio-industrial en el Toledo actual", en Ciudades, culturas y fronteras. IX Coloquio de Geografía Urbana, 9 al 14 de junio de 2008. Sevilla, Consejería de obras Públicas y Transportes, Dirección General de Planificación, pp. 408-421.

GANAU, J. y VILAGRASA, J. (2003): “Ciudades medias en España: posición en la red urbana y procesos urbanos recientes", en Capel, H. (Coord.) Ciudades, arquitectura y espacio urbano, $\mathrm{n}^{\mathrm{o}} 3$ de la Colección Mediterráneo Económico, Almería, Caja Rural Intermediterránea, Instituto de Estudios Socioeconómicos de Cajamar, pp. 37-73.

CORREDOR, B. (2009): "Séptimo Catálogo Español de Buenas Prácticas". Boletín $C F+S$ 41. Madrid. Instituto Juan de Herrera. Disponible en http://habitat.aq.upm.es/boletin/ n41/npres.html

DALDA, J.L. (2007): "Planes y políticas urbanas. La experiencia urbanística de Santiago de Compostela desde 1988". Urban, n 12, pp. 102-125.

ESPEJO, C. (2008): "El papel de los instrumentos de planificación en las dinámicas productivas y territoriales", en Turismo y desarrollo local, Cuenca, Universidad de Castilla-La Mancha, pp. 161-170.

ESPEJO, C. (2011): "El paisaje como recurso turístico", en Retos y perspectivas de la gestión del paisaje de Canarias”, Santa Cruz de Tenerife, Universidad Internacional Menéndez Pelayo y Observatorio del Paisaje de Canarias, pp. 436-461.

ESTÉVEZ, X. (2001): “Santiago de Compostela, conservación y transformación”. Arbor CLXX, 671-672, pp. 473-488.

INSTITUTO GALEGO DA VIVIENDA E SOLO (2008): “Casco Histórico de Santiago de Compostela. Área de rehabilitación de Centro Histórico", disponible en: Xunta de Galicia https://ari-igvs.xunta.gal/es/node/52. 
LALANA, J.L. (2011): "El paisaje urbano histórico: modas, paradigmas y olvidos". Ciudades: Revista del Instituto Universitario de Urbanística de la Universidad de Valladolid, $\mathrm{n}^{\mathrm{o}}$ 14, pp. 15-38.

LÓPEZ, A. (2005): "Desarrollo sostenible: medioambiente y turismo en las ciudades históricas: El caso de Toledo", Observatorio Medioambiental, no 8, pp. 331-344.

MANERO, F. (2011): "En defensa de la identidad difuminada: estrategias de creatividad y promoción turística en ciudades medias. El caso de Castilla y León”. Investigaciones Geográficas, nº 56, pp. 31-47.

MONTERROSO, J.M. (2007): "El centro histórico. La creación de una conciencia cultural. El caso de Santiago de Compostela”, en Actas do Seminário Centros Históricos: Passado e Presente, pp. 39-69.

MUÑIZ, S., FREIRE, M. y RAMOS, A. (2016): "Problemática de la rehabilitación de inmuebles para establecimientos hoteleros en Santiago de Compostela. Algunos ejemplos", en Villegas, L.M. (Dir.), Congreso Latinoamericano sobre patología de la construcción, tecnología de la rehabilitación y gestión del patrimonio: REHABEND 2014, Santander, 1-4 de abril de 2014, pp. 1918-1925.

PANADERO, M. y PILLET, F. (1990): "Castilla-La Mancha”, en García, J.M. y Sotelo, J.A. (Eds.) La España de las Autonomías. Espacios y Sociedades. Serie Mayor. Madrid, Editorial Síntesis, pp. 291-330.

PARIS, M. (2013): "De los centros urbanos consolidados a los lugares de centralidad: una propuesta metodológica para su estudio". Ciudades: Revista del Instituto Universitario de Urbanística de la Universidad de Valladolid, $\mathrm{n}^{\circ}$ 16, pp. 47-69.

PÉREZ, Y. y LOIS, R.C. (2016): "El perfil del visitante en Santiago de Compostela: tradición y actualidad", Cuadernos de Turismo, n 37, pp. 305-322.

PRECEDO, A., REVILLA, A. y MÍGUEZ, A. (2007): "El turismo cultural como factor estratégico de desarrollo: el Camino de Santiago", Estudios Geográficos, n 262, pp. 205-234.

PROGRAMA DE BUENAS PRÁCTICAS (2002): Protección y rehabilitación de la ciudad histórica e integración con su entorno natural (Santiago de Compostela, España). Disponible en http://habitat.aq.upm.es/bpes/onu02/bp205.html

SANTOS, X.M. (2006): "El Camino de Santiago: turistas y peregrinos hacia Compostela", Cuadernos de Turismo, $\mathrm{n}^{\circ} 18$, pp. 135-150.

SANTOS, X.M. y LOIS, R. (Coords.) (2005): Desarrollo turístico sostenible en ciudades históricas. Santiago de Compostela, Lugo, Ayuntamiento de Lugo.

SOMOZA, J. (2007): "Nuevos contenedores culturales y cambios en la centralidad intraurbana”. VIII Coloquio y Jornadas de Campo de Geografía Urbana, 19-24 de junio de 2006. Illes Balears, pp. 247-259.

SOTELO, M. (2012): “Turismo y ciudades patrimonio: estudio de caso, Santiago de Compostela", M + A Revista Electrónic@de Medio Ambiente, $\mathrm{n}^{\circ}$ 12, pp.62-107.

TROITIÑO, M.A. (2003): "La protección, recuperación y revitalización funcional de los centros históricos”. en Capel, H. (Coord.) Ciudades, arquitectura y espacio urbano, $\mathrm{n}^{\circ} 3$ de la Colección Mediterráneo Económico, Almería, Caja Rural Intermediterránea, Instituto de Estudios Socioeconómicos de Cajamar, pp. 131-160. 
TROITIÑO, M.A.; BRANOIS, D.; DEL RÍO, I.; DE LA CALLE, M.; GUTIÉRREZ, J.; LOBO, P. y MARTÍN, F. (1995): "El turismo en las ciudades históricas", Polígonos, $\mathrm{n}^{\circ}$ 5, pp. 49-65.

TROITIÑO, M.A. et al. (1998): "Toledo: problemática e implicaciones urbanas del turismo", Ería, no 47, pp. 299-325.

UNESCO (2007): Centros históricos para todos. Un enfoque social y humano para una revitalización sostenible. Folleto destinado a las autoridades municipales. Folleto recopilado por Laure Veirier, Consultora (Interstices), en colaboración con expertos del Comité de Dirección, División de Ciencias Sociales, Investigación y Desarrollo de Políticas.

VARELA, J.A. (2005): Promoción turística conjunta de ciudades atlánticas "Patrimonio de la Humanidad. Lugo, Ayuntamiento.

VAZQUEZ, C. y APARICIO, A.E. (2007): "Los servicios", en Pillet, F. (Coord.) Geografía de Castilla-La Mancha, Ciudad Real, Biblioteca Añil, pp. 273-290.

ZARATE, M.A. (2008): "Estrategias de dinamización turística en una ciudad Patrimonio de la Humanidad. Toledo", en Troitiño, M.A., García, J.S. y García, M. Destinos turísticos: viejos problemas ¿nuevas soluciones? X Coloquio de Geografía del Turismo, Ocio y Recreación. Ediciones de la Universidad de Castilla-La Mancha. Colección Estudios, $\mathrm{n}^{\circ}$ 121, pp. 354-368. 
